\title{
THE CONVECTIVE STORM INITIATION PROJECT
}

by Keith A. Browning, Alan M. Blyth, Peter A. Clark, Ulrich Corsmeier, Cyril J. Morcrette, Judith L. Agnew, Sue P. Ballard, Dave Bamber, Christian Barthlott, Lindsay J. Bennett, Karl M. Beswick, Mark Bitter, Karen E. Bozier, Barbara J. Brooks, Chris G. Collier, Fay Davies, Bernhard Deny, Mark A. Dixon, Thomas Feuerle, Richard M. Forbes, Catherine Gafarard, Malcolm D. Gray, Rolf Hankers, Tim J. Hewison, Norbert Kalthoff, Samiro Khodayar, Martin Kohler, Christoph Kottmeier, Stephan Kraut, Michael Kunz, Darcy N. Ladd, Humphrey W. Lean, Jürgen Lenfant, Zhihong Li, John Marsham, James McGregor, Stephan D. Mobbs, John Nicol, Emily Norton, Douglas J. Parker, Felicity Perry, Markus Ramatschi, Hugo M. A. Ricketts, Nigel M. Roberts, Andrew Russell, Helmut Schulz, Elizabeth C. Slack, Geraint Vaughan, Joe Waight, David P. Wareing, Robert J. Watson, Ann R. Webb, and Andreas Wieser

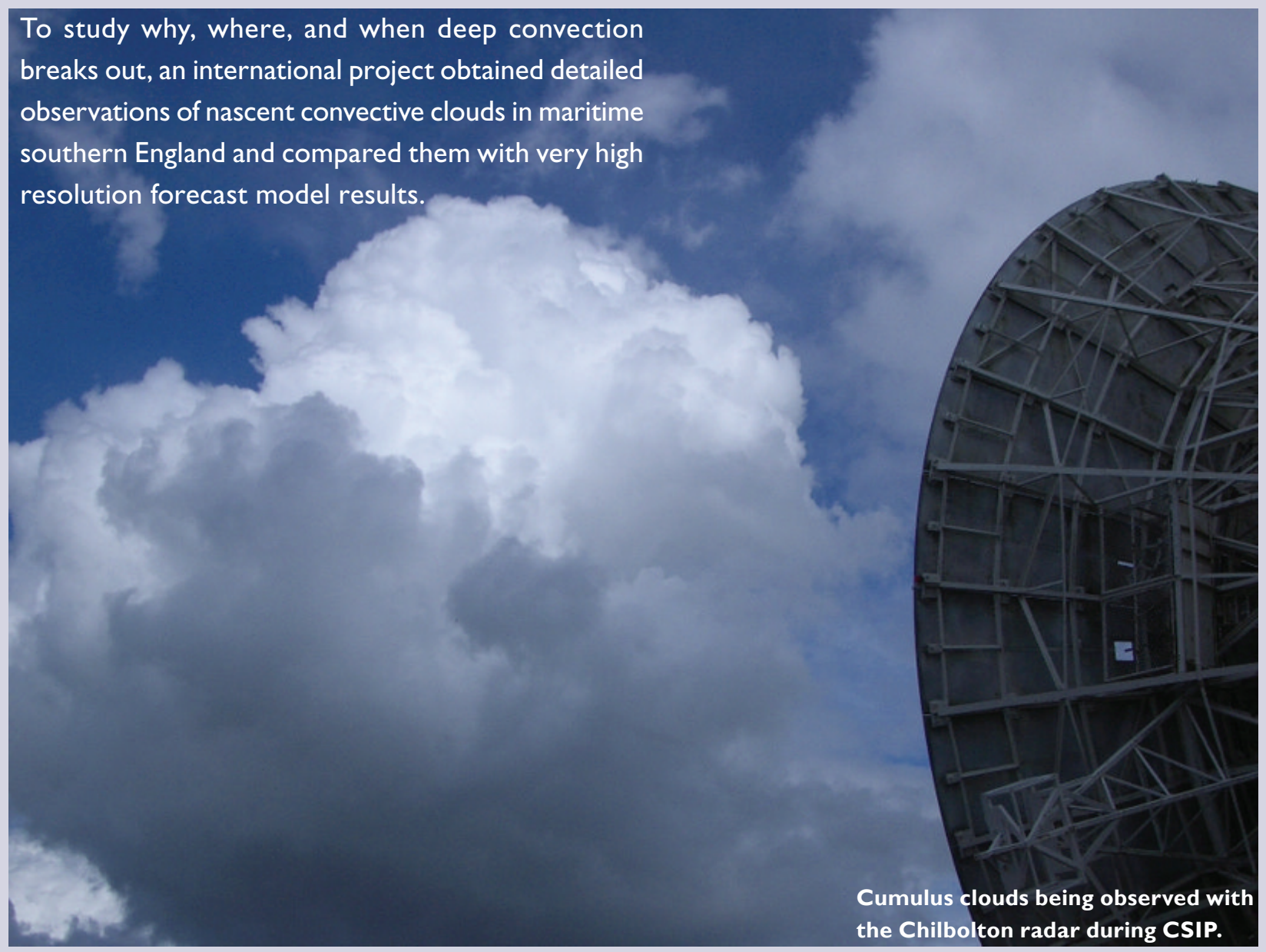

looding caused by heavy rain is a problem that is - motivating renewed research in several countries and it is a major focus for international activities, such as the World Weather Research Program. One of the greatest uncertainties in generating warnings of possible flood situations is in the prediction of the local distribution and timing of the rain. Thunderstorms - and rain associated with deep convection in general-are an important ingredient in many highimpact events, such as flash floods, but the present capability for forecasting convection is especially poor. Such events are highly localized 
and very high resolution (of the order of 1-km grid) numerical weather prediction models are needed to represent them. The triggering of deep convection is well understood in broad terms (e.g., Bennett et al. 2006), but not yet in sufficient detail to know how best to represent it within the models. A key task facing the meteorological community is thus to gain a better understanding of why deep convection breaks out precisely where and when it does and then to use such an understanding in the development of improved NWP models. These were the goals of a recent experiment in the United Kingdom known as the Convective Storm Initiation Project (CSIP).

CSIP was one of three complementary field campaigns. One of these, known as the International $\mathrm{H}_{2} \mathrm{O}$ Project (IHOP_2002; Weckwerth et al. 2004), during the summer of 2002 in the U.S. southern Great Plains, was in a region characterized by large convective instability and strong capping inversions. The local orographic variations in this region are small and generally not critical to the triggering of convection. Another campaign, known as the Convective and Orographically Induced Precipitation Study (COPS), during summer 2007, was in southwestern Germany/eastern France; this region is also characterized by large convective instability but with a major orographic influence. The CSIP field campaigns during the summers of 2004 and 2005, on the other hand, were in a region of the United Kingdom characterized by an intermediate level of orography together with nearby coastlines. The mainly maritime nature of the British climate and the remoteness of any major mountainous areas means that the con- vective instability and capping inversions are often quite weak on convective occasions. Only one of the cases encountered during CSIP was due to convection originating from a layer above the boundary layer; all of the other cases were due to convection initiating in the boundary layer. Elevated convective initiation events were much more common in the IHOP_2002 experiment, where about half the events were of that kind (Wilson and Roberts 2006).

\section{SCIENCE ISSUES ADDRESSED BY CSIP. A}

characteristic feature of the atmosphere in situations leading to the outbreak of deep convection is the stable-layer phenomenon we refer to in this article as a lid. A lid is a layer of warm, dry air that traps air of high wet-bulb potential temperature $\left(\theta_{w}\right)$, usually in the boundary layer, beneath potentially colder air in the middle and upper troposphere. The nature of lids is illustrated by the sounding in Fig. 1. Imagine a parcel of warm, moist air originating close to the surface with $\theta_{w}=14^{\circ} \mathrm{C}$. If it were lifted moist adiabatically (along the thin curve in Fig. 1), it would be warmer than its environment at most levels up to $480 \mathrm{hPa}$; the dark-gray shaded area in Fig. 1 is a measure of the convective available potential energy (CAPE). However, this sounding also shows a relatively dry, warm layer between 740 and $610 \mathrm{hPa}$ (lightly shaded) where this is not so. If the parcel were lifted to these levels it would be negatively buoyant. Such layers give rise to so-called convective inhibition (CIN) and they act as lids that tend to inhibit the onset of deep convection. The lid in Fig. 1 is higher than that typically observed on thunderstorm days in the U.S.
AFFILIATIONS: BROWNING, MoRCRETTE, AND NiCOL-Department of Meteorology, University of Reading, Reading, United Kingdom; Blyth, Bennett, Brooks, Marsham, Mobbs, Parker, and PerRY - Institute for Atmospheric Science, School of Earth and Environment, University of Leeds, Leeds, United Kingdom; CLARK, Ballard, Dixon, Forbes, Lean, LI, and Roberts-Joint Centre for Mesoscale Meteorology, Met Office, and University of Reading, Reading, United Kingdom; Corsmeier, Barthlott, Deny, Kalthoff, Khodayar, Kohler, Kottmeier, Kraut, Kunz, Lenfant, and WieserInstitut für Meteorologie und Klimaforschung, Forschungszentrum Karlsruhe/Universität Karlsruhe, Karlsruhe, Germany; AgnewRadio Communications Research Unit, Space Science and Technology Department, Rutherford Appleton Laboratory, Chilton, United Kingdom; BAMBER AND McGregor-Cardington Field Site, Met Office, Cardington Airfield, United Kingdom; Beswick, Gray, Norton, Ricketts, Russell, Vaughan, And WebB-School of Earth, Atmospheric, and Environmental Sciences, University of Manchester, Manchester, United Kingdom; Bitter, Feuerle, Hankers, AND SCHULZ-Institut für Flugführung, Universität Braunschweig, Braunschweig, Germany; Bozier, Collier, AND DaVIes-School of Environment and Life Sciences, University of Salford, Salford, United Kingdom; Gaffard And HeWISON-Met Office, Exeter, United Kingdom; LADD, SLACK, AND WAIGHT-CCLRC Chilbolton Observatory, Chilbolton, United Kingdom; RAMATSCHIDepartment I: Geodesy and Remote Sensing, GFZ—Potsdam, Potsdam, Germany; WATSON-Department of Electronic and Electrical Engineering, University of Bath, Bath, United Kingdom; WAREING-Department of Physics, University of Wales at

Aberystwyth, Aberystwyth, United Kingdom CORRESPONDING AUTHOR: Alan M. Blyth, Institute for Atmospheric Science, School of Earth and Environment, University of Leeds, Leeds LS2 9JT, United Kingdom

E-mail: blyth@env.leeds.ac.uk

The abstract for this article can be found in this issue, following the table of contents.

DOI:I0.II75/BAMS-88-12-1939

In final form 8 May 2007

(C2007 American Meteorological Society 
Great Plains region where IHOP was conducted (e.g., Weckwerth et al. 2004).

A lid assists in the buildup of latent instability by allowing warm, moist air to be bottled up at low levels, thereby increasing CAPE. However, to realize the potential for deep convection, it is necessary for the low-level air eventually to be able to penetrate the lid. One way to achieve this is through progressive warming and/or moistening of the low-level air, perhaps as part of a diurnal trend. Identifying precisely where the convection will initially break through is a major challenge for prediction.

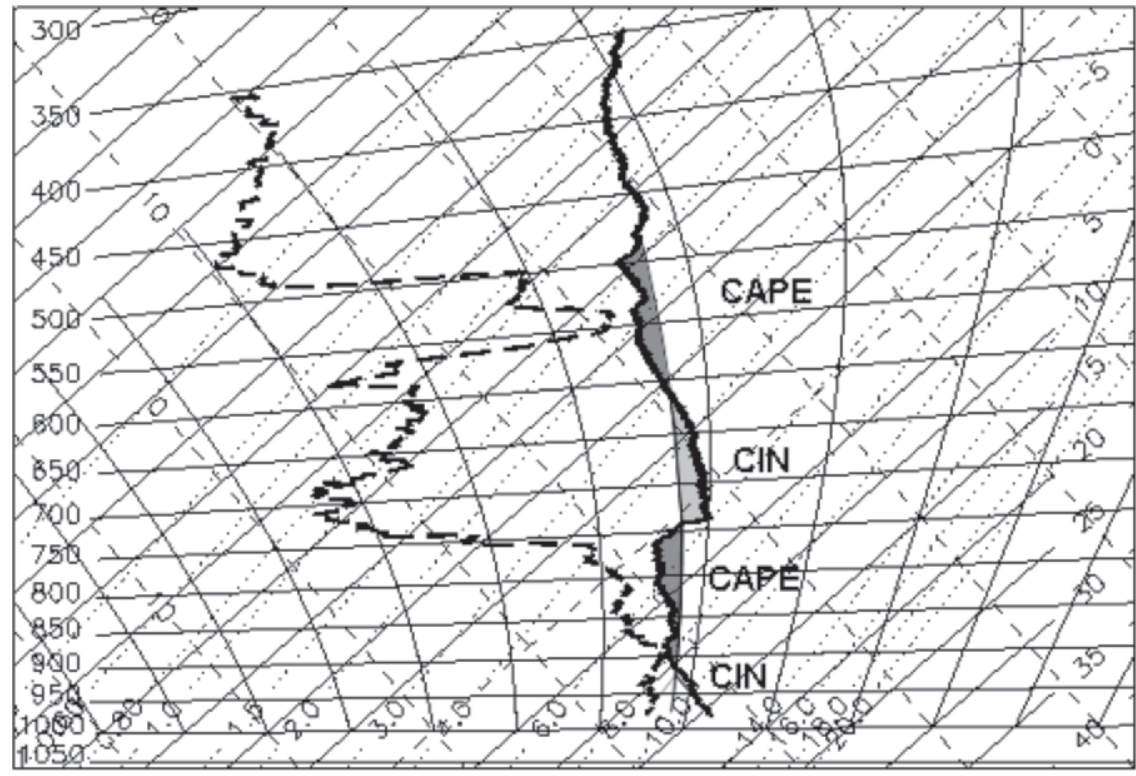

FIG. I. Tephigram for radiosonde launched from Bath at II00 UTC on I5 Jun 2005 (IOP I). The CAPE and CIN are shaded dark and light gray, respectively; the thin solid line partially bounding these areas is the $14^{\circ} \mathrm{C}$ saturated adiabat representing a parcel that ascends unmixed from the boundary layer.

The site of the initial out-

break will be influenced partly by any spatial variability in the temperature and/or humidity of the boundary layer air, perhaps on scales too small to be resolved by conventional observations (e.g., Weckwerth 2000). Sometimes the variability is due to the effects of variable terrain height or differing land (or sea) surface characteristics, or perhaps differential shadowing by cloud at higher levels.

Variability in the characteristics of the boundary layer air may not, however, be the sole or even the principal determinant of precisely where the first deep convection will break out. The other factor that is important in the United Kingdom is variability in the strength of the lid itself. This can be either intrinsic variability owing to the differing source regions for different parts of the lid, or local variability owing to some mesoscale dynamical mechanism that lifts the lid locally. Such lifting will cool the lid rapidly (at the dryadiabatic rate), thereby eliminating the CIN and enabling boundary layer air of high $\theta_{w}$ (ascending moist adiabatically) to penetrate it.

Even a small vertical displacement of the lid may be sufficient to allow the underlying air to pen- etrate buoyantly upward. This is illustrated in Fig. 2, which depicts another low-CIN situation, common in a maritime climate such as the United Kingdom's, in which a mere $15 \mathrm{hPa}$ of lift (i.e., about $150 \mathrm{~m}$ ) is enough to initiate deep convection. Sometimes the presence or absence of an appropriate local lifting mechanism will determine whether deep convection will be triggered at all: it can make the difference between an entirely dry day and the occurrence of
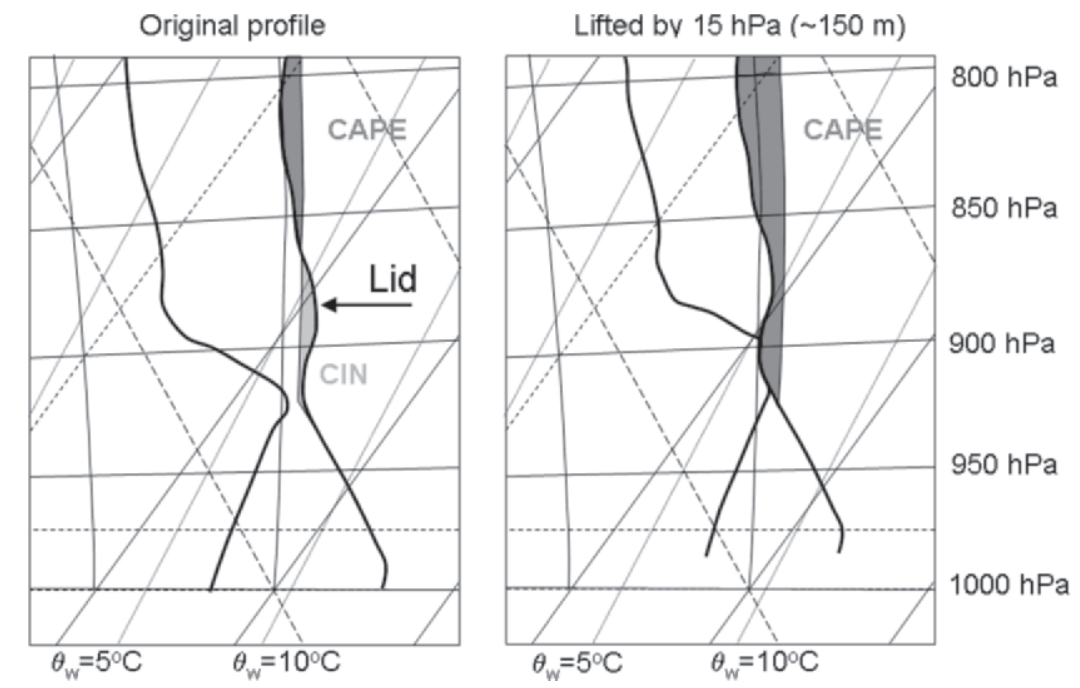

Fig. 2. Illustration of how adiabatic lifting of a profile by as little as $15 \mathrm{hPa}$ $(\sim 150 \mathrm{~m})$ can increase the CAPE and completely eliminate the CIN. The original profile is shown on the left and the lifted profile on the right. (Adapted from Morcrette et al. 2006.) 
a severe rainstorm. On other occasions, when the diurnal warming of the boundary layer is sufficient on its own to initiate deep convection, although the distribution of $\theta_{w}$ within the boundary layer may determine broadly where the initial convection will occur, the local distribution in the lifting of a lid (or local variability in the strength of an unperturbed lid) will often still be the key to determining precisely where and when the first convection breaks out. Predicting the location of the first outbreak accurately is crucial because, once the first convective storm has formed, secondary processes often take over that tend to trigger further convection initiation preferentially in the vicinity of that storm.

It has long been recognized that local lifting often occurs in the form of boundary layer convergence lines, detectable by satellite (Purdom 1982) and seen by radar as fine lines of enhanced reflectivity (Wilson and Schreiber 1986). Convergence lines were particularly common during IHOP_2002, and where they intersected with other convergence lines they were often preferred locations for enhanced ascent and convective initiation. Some convergence lines are due to topographical effects such as those produced by variations in terrain height or land/water boundaries. During the Vertical Transport and Orography (VERTIKATOR) project in southwestern Germany in 2002 , topographically induced convergence lines were found to trigger deep convection over the Black Forest mountains (Barthlott et al. 2006). Others are due to variations in land use or land wetness, with associated variations in Bowen ratio (Weckwerth and Parsons 2006). Also, under conditions of strong low-level shear, horizontal convective rolls, that is, parallel lines of convergence separated by regions of divergence, oriented roughly along the direction of the shear, are an intrinsic dynamical feature of mixed boundary layers.

The triggering of deep convection that any of the above kinds of convergence line produces is referred to as primary initiation. Once the first storm has developed, this can, as already mentioned, lead to secondary initiation. The secondary initiation may arise from lifting by gravity waves emanating from an earlier storm or from lifting along its rain-chilled outflow (gust front) as it advances like a density current. According to Wilson and Roberts (2006), just over half the convective storm complexes associated with initiation episodes in IHOP_2002, and probably most of the cases with surface-based convection, produced gust fronts. Most of the long-lived events were associated with gust fronts.

Lifting can also result from ascent induced beneath traveling positive anomalies in potential vorticity (PV) occurring at upper levels. These PV anomalies are associated with tropopause depressions or folds (Hoskins et al. 1985). Such PV anomalies are often encountered in Europe and presumably in other middle- or high-latitude locations, and their influence on precipitation has been examined, for example, during the Mesoscale Alpine Programme (MAP; Bougeault et al. 2001). They are especially important because as well as reducing the CIN through the induced lifting, they also increase the CAPE owing to the pool of cold air at middle and upper levels that always accompanies them.

In the remainder of this article we shall i) provide an overview of the CSIP field campaign, ii) present examples from CSIP of the types of convection initiation phenomena that are typical in the United Kingdom, showing the way in which certain kinds of observational data are able to reveal these phenomena, and iii) explain how the analyses of data from the field campaign will be used in the development of an improved very high resolution NWP model for operational use. A large database has been accumulated from CSIP. Analysis is still at an early stage and the material presented here is intended to provide an overview of important processes, and of opportunities for improving forecasting models, rather than to give definitive results.

THE CSIP FIELD CAMPAIGN. The main field campaign was conducted over southern England during June, July, and August 2005. It benefited from an earlier pilot campaign in the same region in July 2004. An overview of the observational setup is given in Fig. 3. The Operations Centre was based at Chilbolton (at the center of the range rings in Fig. 3). This is the site of the Chilbolton radar facility with its 25-m steerable dish (Goddard et al. 1994). Other instruments were sited within range of the Chilbolton radars, as shown in Fig. 3. Many of them were new or upgraded systems operated as part of the recently established U.K. Universities Facility for Atmospheric Measurement (UFAM) by staff from the Universities of Aberystwyth, Leeds, Manchester, Reading, and Salford. The others were state-of-theart instruments from the Institute for Meteorology and Climate Research (IMK), Karlsruhe, Germany; the Rutherford Appleton Laboratory; the Met Office; GeoForschungsZentrum (GFZ) - Potsdam, and the University of Bath.

The observations. The set of instruments deployed in southern England for CSIP included 
- $\quad$ 1275- $\mathrm{MHz}$ (L band), 3-GHz (S band), and 35-GHz Doppler radars at Chilbolton (the $3-\mathrm{GHz}$ radar is also a polarization radar);

- UHF wind profiler;

- three sodars;

- two Doppler lidars;

- ozone lidar;

- water vapor lidar;

- three microwave radiometers;

- ceilometer;

- serial ascents at 1- to 2-h intervals from six mobile rawinsonde stations, plus serial ascents from three Met Office operational systems (giving a total of about 800 soundings associated with CSIP);

- network of 16 automatic weather stations;

- two instrumented light aircraft (DO 128 and Cessna 182);

- network of five GFZ GPS integrated water vapor stations; and

- two energy balance stations.

These instruments were within a region of good coverage by the Met Office network of surface stations and the U.K. operational weather radar network, which provided maps of estimated rainfall intensity at resolutions mainly between 1 and $2 \mathrm{~km}$ every $5 \mathrm{~min}$ for single radars and every $15 \mathrm{~min}$ for composite displays. Extensive use was made of infrared, water vapor, and high-resolution visible imagery every $15 \mathrm{~min}$ from Meteosat-8, the Meteosat Second Generation (MSG) satellite (Schmetz et al. 2002), and every $10 \mathrm{~min}$ from Meteosat-6. These products were used not only for post-storm analysis, but also for nowcasting to guide deployment of aircraft and serial rawinsondes. Hourly surface wind and convergence analyses from the Met Office NIMROD system (NIMROD is a fully automated system for weather analysis and nowcasting based around a network of C-band rainfall radars; Golding 1998) were also particularly useful for this purpose.

Forecasting products. The most useful products for forecasting convection initiation were those derived from the operational mesoscale version of the Unified Model (Cullen 1993), which was run every $6 \mathrm{~h}$ out to $\mathrm{T}+36 \mathrm{~h}$ on a $12-\mathrm{km}$ grid. These runs were supplemented by special runs from a $4-\mathrm{km}$ version of the Unified Model being developed by Met Office staff at the Joint Centre for Mesoscale Meteorology (JCMM) at the University of Reading. An example of these products is shown in Fig. 4. Figures 4a,b depict the $\mathrm{T}+13 \mathrm{~h}$ forecasts of rainfall intensity in the CSIP operating area on 29 June 2005, from the 12- and $4-\mathrm{km}$ versions of the model, respectively. Figure $4 \mathrm{c}$ depicts the corresponding observed pattern of rainfall obtained by the weather radar network.

Both versions of the model use the new nonhydrostatic, fully compressible deep atmosphere dynamical core (Davies et al. 2005). The $12-\mathrm{km}$ model uses a 3 -h, 3DVAR data assimilation cycle (Lorenc et al. 2000) supplemented by assimilation of cloud and radar-based rainfall information using nudging techniques (Jones and Macpherson 1997). It provides a well-proven mesoscale background but uses a parameterization of deep convection based on Gregory and Rowntree (1990). Essentially, it is an equilibrium mass-flux scheme, tending to respond to CAPE, and it gives only a general indication of areas where convection is possible, with little finescale detail. The $4-\mathrm{km}$ model, run one-way nested within the $12-\mathrm{km}$ model and using the same initial conditions, follows its mesoscale

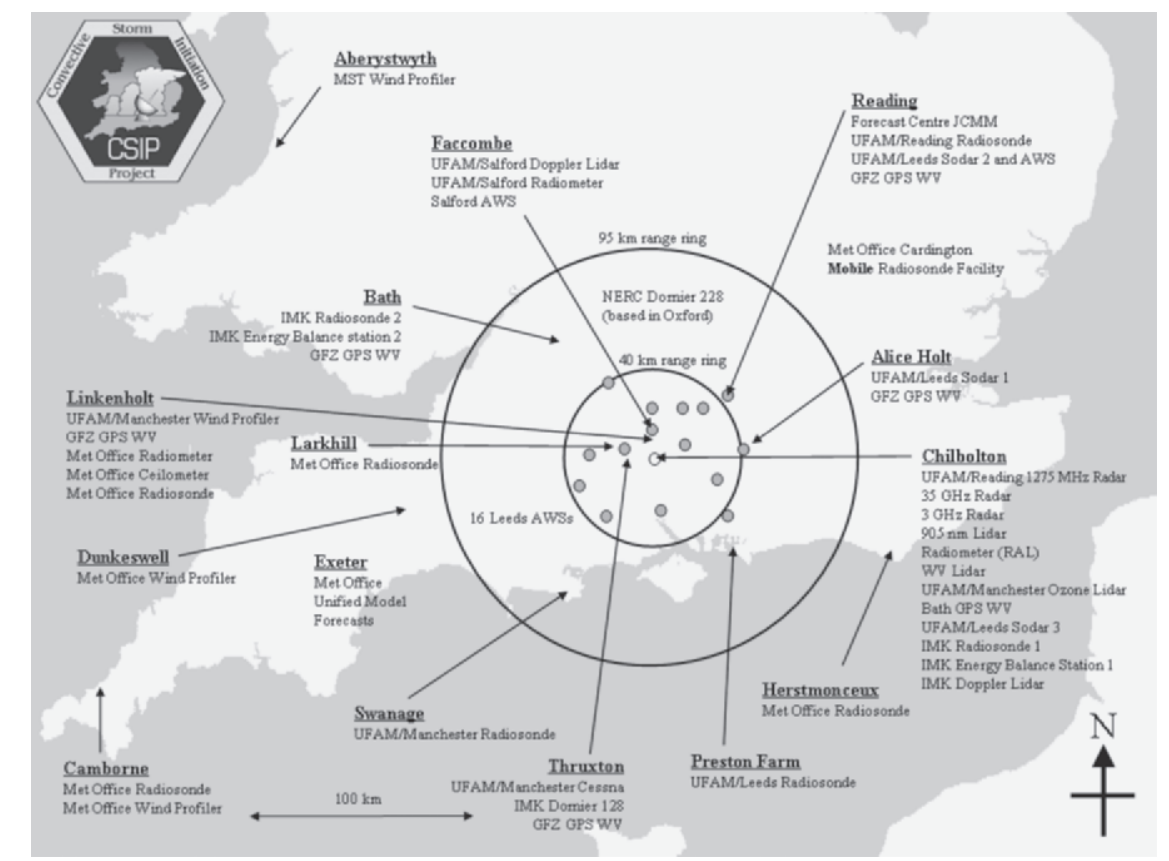

FIg. 3. Map showing locations of instruments deployed in southern Britain during CSIP in Jun, Jul, and Aug 2005. The shaded circles represent the position of the Automatic Weather Stations (AWSs). 

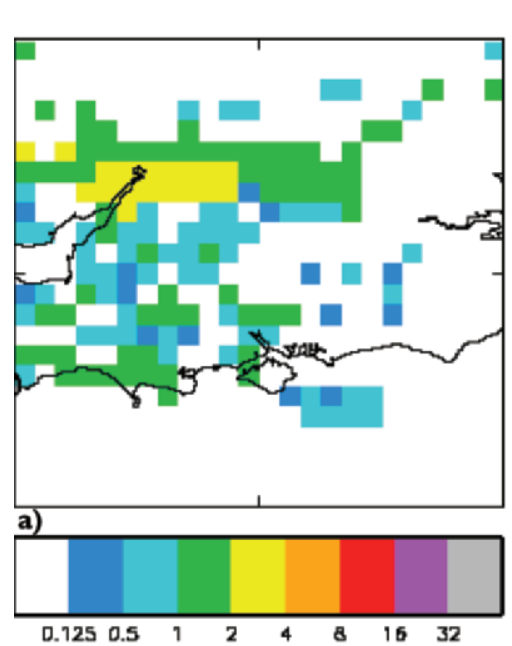
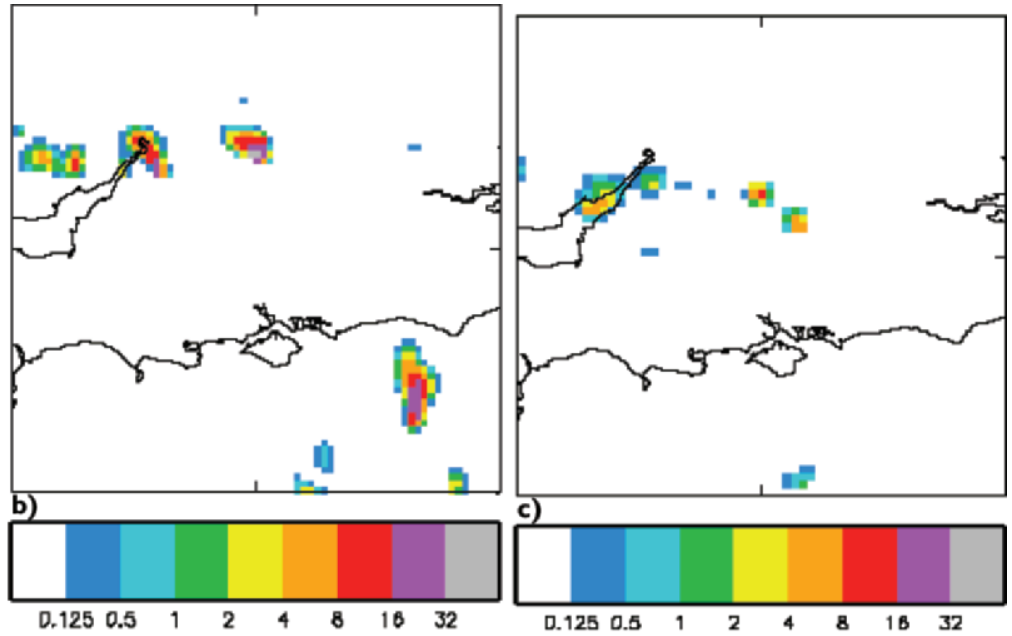

Fig. 4. Example of a 13-h precipitation forecast from the Met Office Unified Model run using (from left to right) (a) a I2-km grid and (b) a 4-km grid, compared with (c) the rainfall rate observed by the weather radar network at 1300 UTC on 29 Jun 2005 (IOP 5). Key gives rainfall intensity in $\mathrm{mm} \mathrm{h}^{-1}$.

evolution closely but benefits in two ways. First, it resolves surface forcing and the resulting flow much better, and so it often provides better guidance as to the areas where surface-forced initiation is most likely. Second, while the mass-flux parameterization is still used, its mass flux is limited in such a way as to ensure that deep convection is treated largely explicitly. Although a 4-km grid is not ideal, it has been shown to behave adequately when compared with 1-km versions of the same model in cases of intense convection. In particular, mechanisms leading to mesoscale organization are captured quite well. The inadequate resolution does tend to lead to a delay in initiation on the order of an hour, but spatial guidance is often superior to that from the $12-\mathrm{km}$ model.

Another useful product for forecasting convection initiation obtained from the operational run of the mesoscale model that we wish to highlight was a time-height plot of forecast $\theta_{s}$, or saturation potential temperature, above the lifting condensation level. Here, $\theta_{s}$ is the dry-bulb temperature read off the $\theta_{w}$ scale as though the air were saturated. The plot has the advantage of showing at a glance the expected evolution of layers of CAPE and of CIN (i.e., lids) with respect to any parcel value of $\theta_{w}$. An example is given in Fig. 5. The upper panel of Fig. 5 shows a lid with $\theta_{s}$ up to

Fig. 5. Met Office 12-km-grid Unified Model forecast of the time-height cross section of (top) $\theta_{s}$ and (bottom) $\theta_{w}$ over Larkhill (see Fig. 3 for location) on II Aug (IOP I4R) and I2 Aug 2005. The white line in the upper plot shows the lifting condensation level; above this the contours and shading represent $\theta_{s}$, and below they represent $\theta$. (Surface values of $\theta$ are specified along the time axis of the upper plot.) 
$17^{\circ} \mathrm{C}$ just above the lifting condensation level (white curve) at heights between 1 and $2 \mathrm{~km}$ from 1530 to 2100 UTC (on day 1). Predicted surface values of $\theta_{w^{2}}$ plotted along the bottom of the lower panel, were not quite high enough during this period for parcels to penetrate the unmodified lid, although the predicted maximum surface value of $\theta_{w}$ at $1600 \mathrm{UTC}\left(16.7^{\circ} \mathrm{C}\right)$ would have produced parcels with a $1^{\circ} \mathrm{C}$ temperature excess at the $4-\mathrm{km}$ level if they could have penetrated the lid. In the event, low-level convergence is believed to have lifted (and hence weakened) the lid locally and allowed convection to penetrate upward to $6 \mathrm{~km}$ at around 1700 UTC. Illustrations of this kind of behavior are shown below.

\section{OBSERVING THE PRESTORM LIDS AND} CONVECTIVE ELEMENTS. CSIP is concerned specifically with initiation of convection, and so it was important to be able to observe the detailed structure of the prestorm boundary layer, of the lid (or lids) capping it, and of convective elements (clear-air thermals, fair-weather cumulus, and cumulus congestus) before, during, and just after they penetrated the lid. Thermodynamic information on the structure of the boundary layer and lids is available in CSIP from the serial rawinsondes and aircraft traverses. This information is supplemented by data from the $3-\mathrm{GHz}$ and $1275-\mathrm{MHz}$ radars at Chilbolton. As shown in the following example, these radars provided important information on the nature and detailed pattern of the prestorm boundary layer, lids, and convection on scales of tens of kilometers down to hundreds of meters.

Two kinds of scattering mechanisms are involved in the detection of the above features by radar. Echoes from the edges of convective elements are generally due to Bragg scattering from refractive index inhomogeneities, mainly from humidity gradients (Doviak and Zrnic 1993). Echoes in the interiors of convective elements are more often due to Rayleigh scattering from large cloud particles, precipitation, or perhaps insects. Layer echoes can be due to either Bragg scatter or Rayleigh from insects. The 3-GHz and 1275-MHz radars are mounted on the same dish and are operated at the same time. Having data simultaneously from the two radars is beneficial in that the different wavelength dependency of Bragg and Rayleigh scattering helps clarify the nature of the targets (scattering by refractive index inhomogeneities is favored at $1275 \mathrm{MHz}$ compared to $3 \mathrm{GHz}$ ).

Figure 6 shows examples of RHI scans from the 3-GHz radar. Figure 6a depicts a layer of low-reflectivity echo from the bottom of a lid above a cloud-free boundary layer prior to the development of significant convection beneath it. Figure 6b depicts echoes not only from a lid some way above the boundary layer, but also from the edges of clear-air thermals and fair-weather cumulus clouds as the top of the convective boundary layer began to rise up toward the lid.
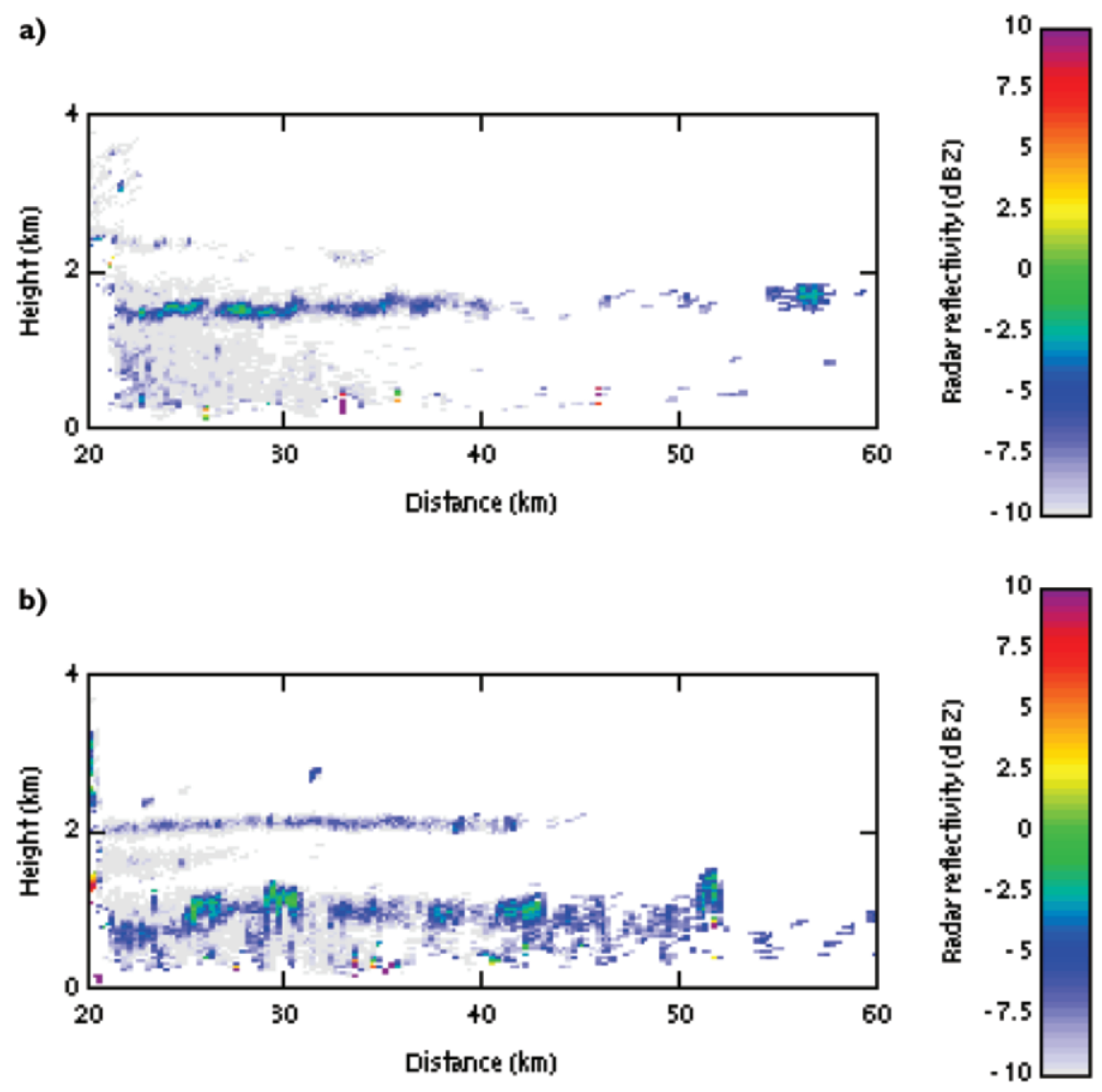

FIG. 6. Two examples of $\mathrm{RHI}$ scans of reflectivity (dBZ) from the 3-GHz radar at Chilbolton showing lids and the outline of thermals: (a) echo from the bottom of a lid without significant convection beneath it; (b) thermals in the boundary layer below the bottom of a lid [at II25 UTC I8 Jul 2005 (IOP 9) and I0II UTC 29 Jun 2005 (IOP 5), respectively]. 
Figure 7 shows another RHI scan from the $3-\mathrm{GHz}$ radar, but this time it shows differential reflectivity $(Z D R)^{1}$ rather than reflectivity $(Z)$. It depicts in green the echoes from the edges of large cumulus congestus clouds as well as from the precipitation particles developing within them. However, unlike in all the other cases during CSIP, where the convection originated from the boundary layer, the convection here was occurring in the form of elevated convection from air being advected above a stable frontal zone that is depicted by multiple red/maroon echo layers. Here the lid that would previously have restrained the convection is no longer evident. The lid would have been situated at the top of the boundary layer air before it was advected from France and lifted above the frontal zone.

The fact that Fig. 7 depicts ZDR rather than $Z$ explains why the echoes from the convection cells are so easily distinguishable from the layer echoes within the stable frontal zone (i.e., green versus red/maroon). The green echoes have low values of ZDR typical of both Bragg scattering from refractive index inhomogeneities at the edges of the convective cells and of Rayleigh scattering from newly developing precipitation. The red/maroon echoes were probably due to elongated insects advected within the frontal zone.

Figure 8, an RHI scan from the $1275-\mathrm{MHz}$ radar, shows an example of the radar signature of cumulus congestus clouds. It depicts the reflectivity from two such clouds, each $3 \mathrm{~km}$ high, that had only recently penetrated a lid capping the boundary layer at about

${ }^{1} \mathrm{ZDR}$ is the ratio between the horizontal and vertical received power and is thus a measure of the oblateness of the scatterers.
$1 \mathrm{~km}$ (Morcrette et al. 2006). In the case of the cloud at 18 - to $20-\mathrm{km}$ range, the radar detects just the Bragg scatter from the refractive index inhomogeneities at the cloud boundaries. In the case of the cloud at 10to $13-\mathrm{km}$ range it may also be detecting the Rayleigh scatter from precipitation particles developing within it; alternatively, it may be seeing mainly Bragg scatter, but from the edges of a cluster of smaller subcells. The breakthrough of convection cells above the lid, as in Fig. 8, often occurs where the lid is lifted locally by some mesoscale mechanism; examples of these mechanisms are presented shortly.

We suspect that mesoscale lifting processes are the mechanism responsible for localizing the initiation of convection on the majority of occasions; however, convective breakthrough can in principle be localized even without local lifting, provided that the lid is weak and there are significant local hot spots or moist anomalies within the boundary layer. Thus, before proceeding to look at the mesoscale lifting mechanisms, we shall present one more radar product used in CSIP-one that can reveal the mesoscale variability essentially in the humidity structure on a roughly horizontal plane within the boundary layer itself. Figure 9 shows the near-surface refractivity $(N)$ field derived from the 1275-MHz radar using the technique pioneered by Fabry et al. (1997). The technique utilizes the change in phase of radar returns from ground targets relative to a reference scan. The reference scan was chosen to correspond to a near-constant refractivity field as determined by observations from the 16 automated weather stations surrounding Chilbolton. During summer daytime conditions, the refractivity field is primarily influenced by variations in humidity, where a change of
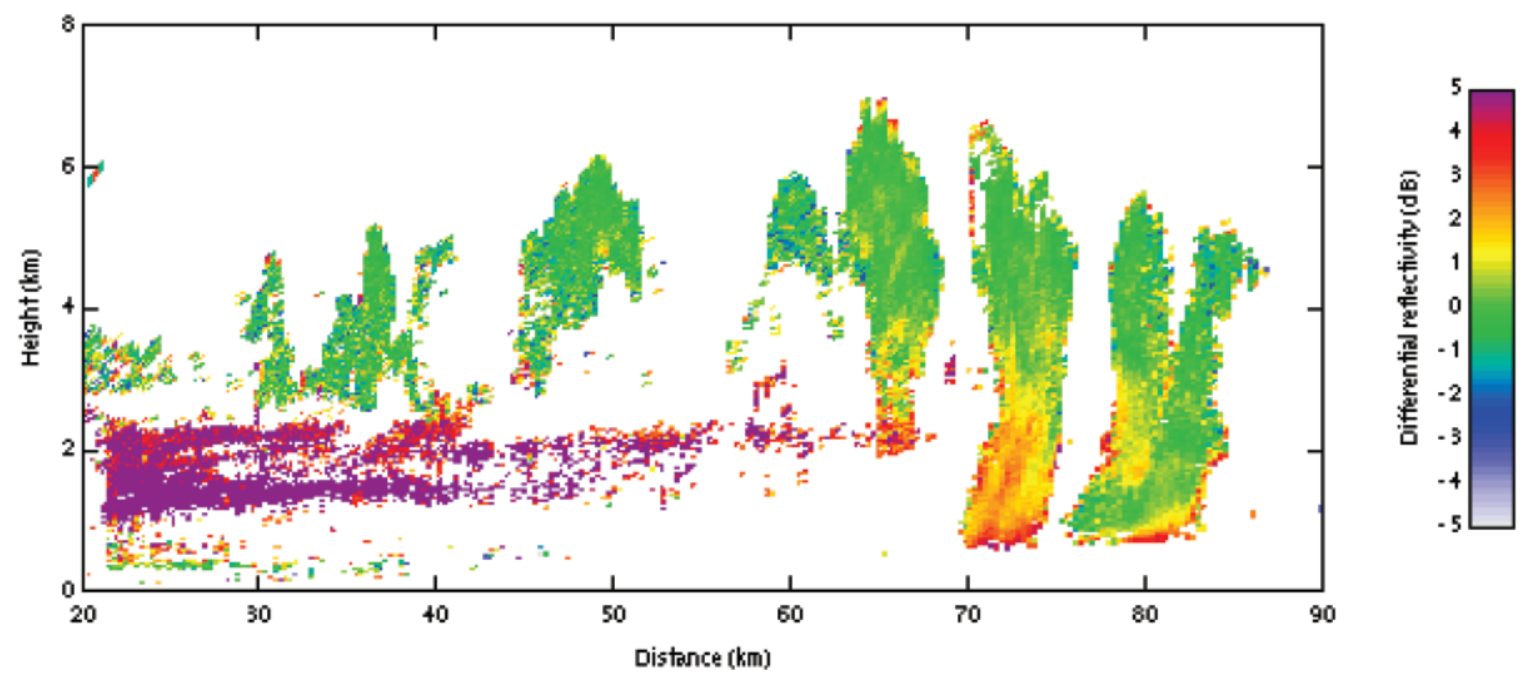

FIG. 7. RHI of differential reflectivity (ZDR), from the 3-GHz Chilbolton radar, at I249 UTC 24 Jun 2005 (IOP 3), showing elevated convection cells forming above a stable frontal zone. 

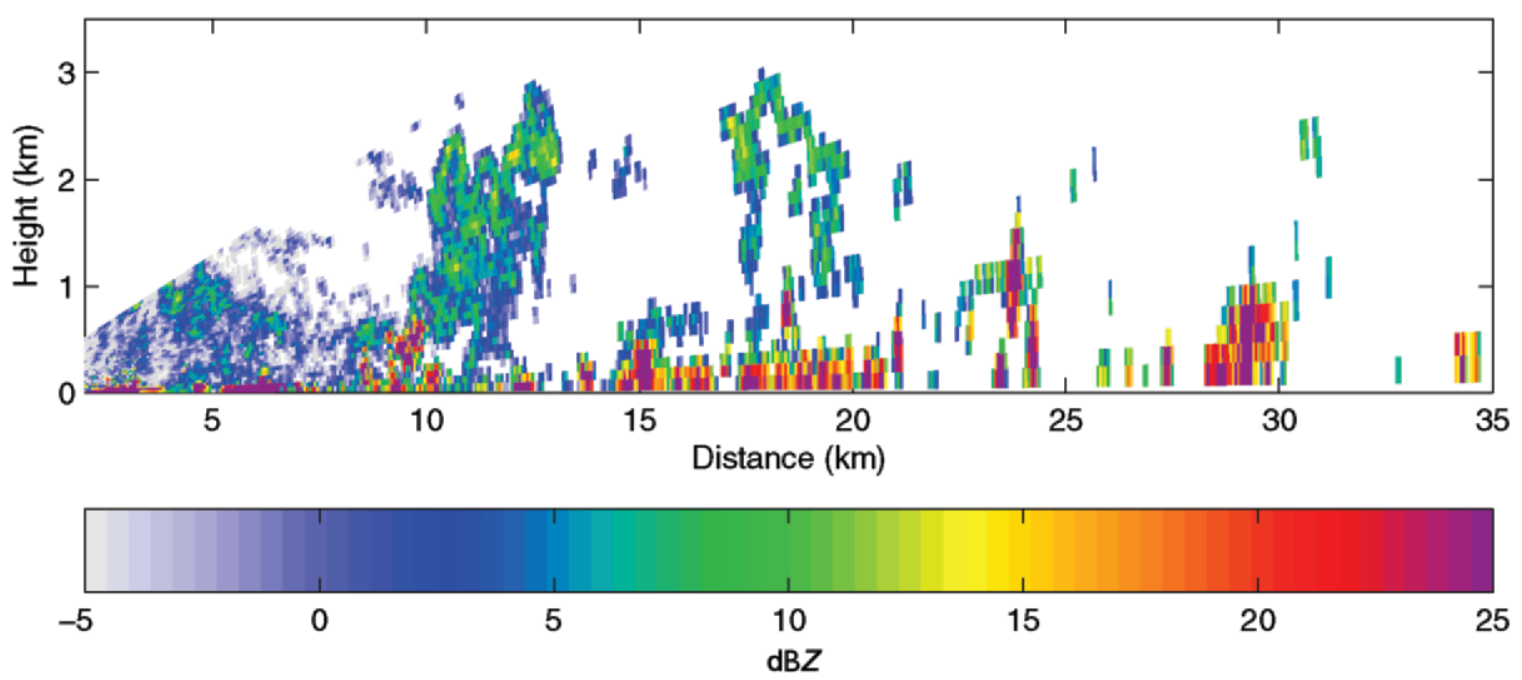

FIG. 8. RHI of reflectivity from the I275-MHz Chilbolton radar at 0928 UTC I0 Jul 2004, showing developing cumulus congestus clouds. The echoes near the ground are a combination of ground clutter and radar returns from insects. (From Morcrette et al. 2006.)

1 unit corresponds to a change in relative humidity of approximately $1 \%$. Although limited mainly to ranges within $30 \mathrm{~km}$ of the radar at Chilbolton, the technique provides valuable insight into scales of variability not easily resolved by the in situ measurements. Figure 9 shows a large gradient in refractivity just to the northwest of the radar (at Chilbolton), corresponding to a relative humidity gradient of approximately $10 \%$. A corresponding gradient in moisture was detected by radiosondes released from Chilbolton and Larkhill, $25 \mathrm{~km}$ west of Chilbolton. Satellite pictures showed that convective clouds developed in the moist region.

\section{OBSERVING THE MESOSCALE FORCING MECHANISMS WITHIN THE BOUNDARY}

LAYER. Localized lifting is usually the key to determining precisely where and when convection will be triggered. Our belief that local variability in boundary layer moisture plays only a secondary role to mesoscale lifting processes in localizing convective initiation is in line with the analyses of IHOP_2002 data by Fabry (2006). A variety of types of mesoscale forcing were observed during the 18 intensive observing periods (IOPs) of the main 2005 field campaign that have been summarized in a report by Browning et al. (2006). Some examples are presented below from these IOPs and also from one of the cases observed during the 2004 pilot project. Three of these examples illustrate forcing from low levels and two illustrate forcing from upper levels.

Examples of boundary layer forcing. We first present examples of primary initiation along convergence lines within the boundary layer. Figure 10 is a visible image showing clouds along a convergence line that trailed persistently downwind from the south coast of southwest England. An RHI scan across this line (Fig. 11) illustrates the effects of the convergence. The reflectivity plot in Fig. 11a and the ZDR plot in Fig. 11b both show two clear-air layers as well as one of the shower clouds that formed along the convergence line (at $53 \mathrm{~km}$ ). Most of the echo in Fig. 11-both layer and convective echo-is probably due to Bragg scattering, that is, low ZDR (green); however, the

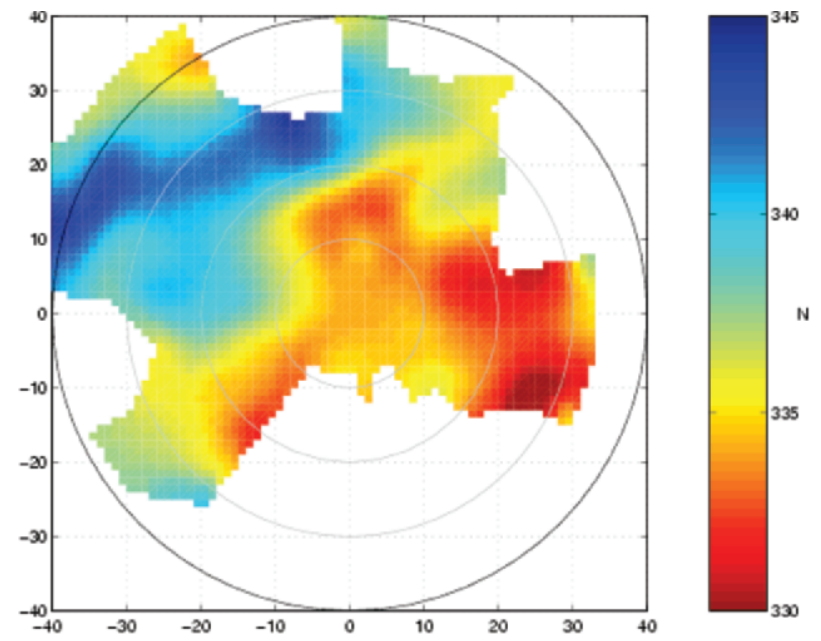

Fig. 9. Refractivity field obtained from the $1275-\mathrm{MHz}$ Chilbolton radar at 1259 UTC 13 Jul 2005 (IOP 8), using the technique described by Fabry et al. (1997). In summer, the changes in refractivity are mainly due to humidity variations. Here, a change in refractivity of $\mathrm{I}$ unit is approximately equal to a change in relative humidity of $1 \%$. 


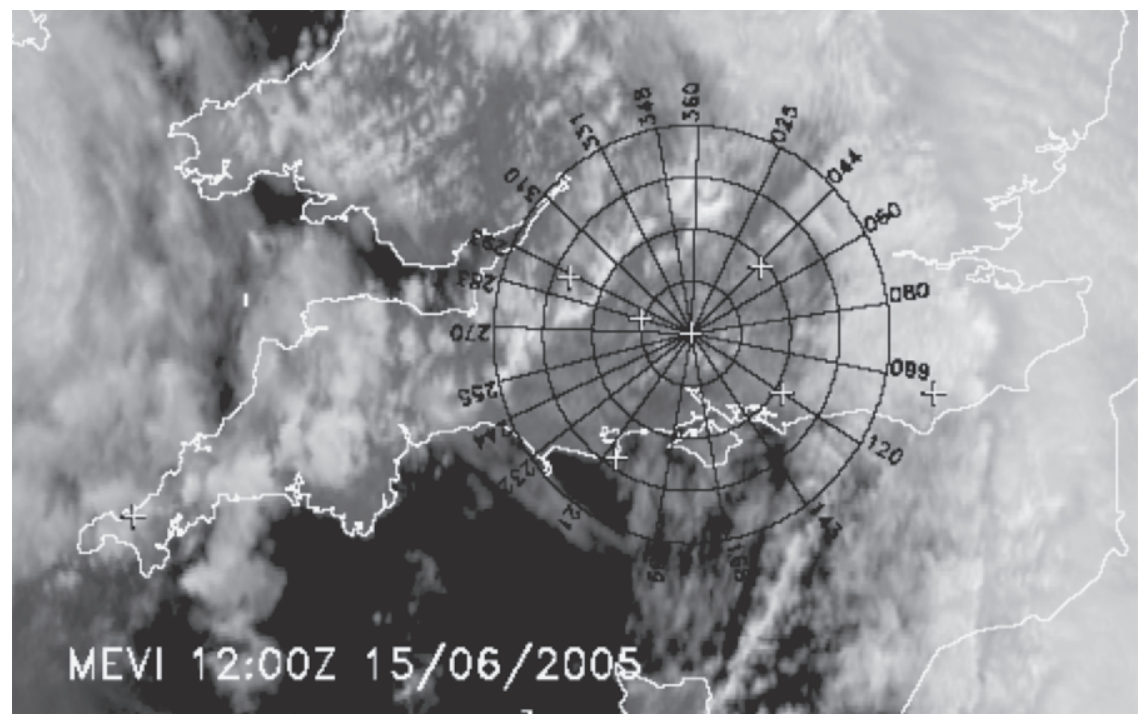

FIG. I0. High-resolution visible image from Meteosat- 8 (MSG) at I200 UTC I5 Jun 2005 (IOP I), showing among other things, convective cloud along a convergence line extending from the south coast toward the northeast. Range rings are centered on Chilbolton and plotted every $25 \mathrm{~km}$. The radial lines correspond to azimuths with low horizons along which series of RHI scans were obtained.

what smoother echo layer at about $2 \mathrm{~km}$ that rises to over $2.5 \mathrm{~km}$ beyond $40 \mathrm{~km}$, reaching a peak where the

low-ZDR echo at the top of the shower cloud may be due to ice particles above the $3 \mathrm{~km} 0^{\circ} \mathrm{C}$ level, and the higher-ZDR echo coinciding with the reflectivity core is due to rain (produced, at least in part, from melting ice rather than from the warm-rain process alone). The undulating echo "layer" around $1 \mathrm{~km}$, detectable from a minimum range out to $50 \mathrm{~km}$, is not so much a layer as an envelope of small convective elements in the boundary layer. Above this, there is another, some- main shower cloud is developing. This echo layer corresponds to the base of the major lid at $750 \mathrm{hPa}$ seen in the sounding in Fig. 1. The small shower cloud and the locally raised lid are both manifestations of the convergence line.

A second example of primary initiation is given in Fig. 12, which shows convective cloud streets along boundary layer convergence lines (horizontal convective rolls) almost parallel to the strong

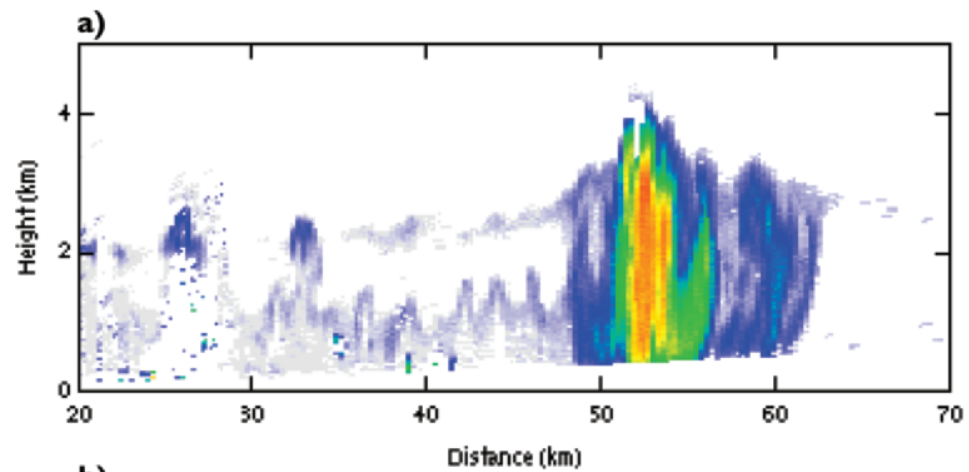

b)

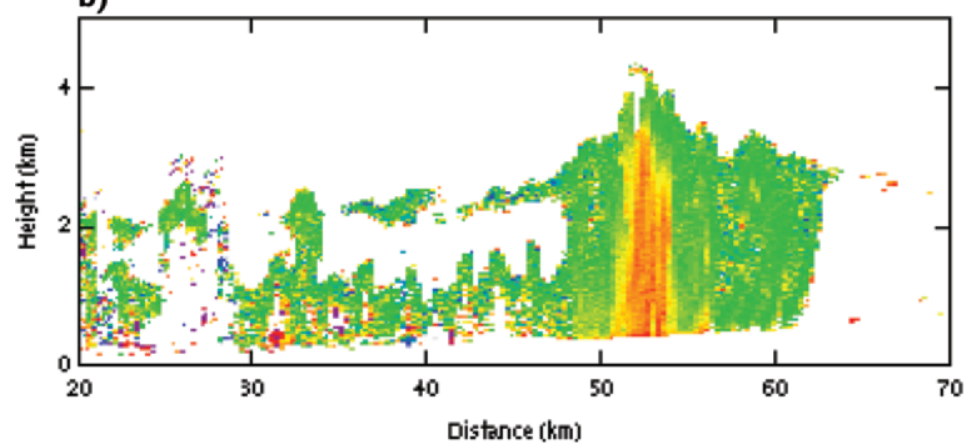

FIG. II. RHIs of (a) reflectivity (dBZ) and (b) differential reflectivity (dB) for a scan across the convergence line in Fig. 10, obtained from the $3-\mathrm{GHz}$ Chilbolton radar at I200 UTC I5 Jun 2005 (IOP I). low-level wind. The clouds
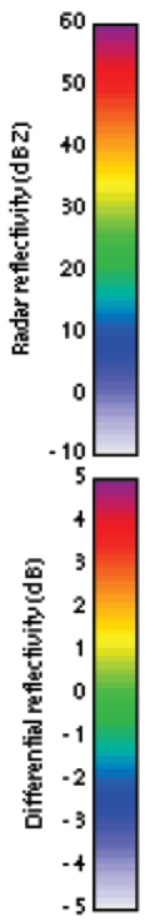

(Fig. 12a) formed as the airflow progressed inland into southern England. They started to develop in the early morning, and by midday they were deep enough to produce some heavy thunderstorms (see the radar network display in Fig. 12b). (About an hour later, one of these storms became sufficiently intense to produce an F2 tornado.) The spacing of the shower lines is due to an intrinsic dynamical organization, but further study of this dataset may indicate the extent to which the shape of the coastline, areas of modest hills, or other factors may have assisted some of the shower lines to become more intense than others. 
Figures 10-12 were given as examples of primary initiation. Next, in Figs. 13-17, we give examples of forcing in which a previous convective storm leads to the initiation of secondary convection.

The visible satellite image in Fig. 13 shows an arc of convective cloud to the southeast of Chilbolton over the English Channel. At the time of Fig. 13, the Met Office network radar showed that a line of new convective showers was developing along this arc (not shown). The arc had formed along the gust front, or leading edge of a cold pool, due to the rain-chilled downdraft from an earlier mesoscale convective system that had formed on the western side of the CSIP area and drifted eastward. Data from the automatic weather stations (AWSs) showed that a temperature drop of up to $8^{\circ} \mathrm{C}$ accompanied the passage of the gust front. Purdom (1982) showed that such visible satellite imagery is useful for identifying this important class of convergence line. The convergence at the gust front showed up as a velocity discontinuity on the Doppler radar plan position indicator (PPI) display-see the arc-shaped transition from green, through yellow, to red (in Fig. 14b) at the leading edge of the main storm area in Fig. 14a.

Sometimes such a gust front shows up as a radar fine line as in Fig. 15a. The reflectivity pattern in this figure shows two clusters of convective showers, with a fine line $10-20 \mathrm{~km}$ ahead of them. The ZDR pattern in Fig. 15b shows the same shower systems (mainly green) at an earlier time, along with the outflow boundary to the east of one of them, characterized by a transition from red to green. Our working hypothesis is that the large values of ZDR along the red parts parts of the fine line are due to insects in the unperturbed boundary layer, whereas the low values of ZDR (green) on the inner edge of the fine line are from Bragg scattering in the relatively insect-free air of recent downdraft origin.

In another example of secondary initiation, a series of parallel lines of convective showers and thunderstorms developed (Fig. 16); the lines were transverse to the overall wind direction. Detailed observational and theoretical analyses (Morcrette et al.
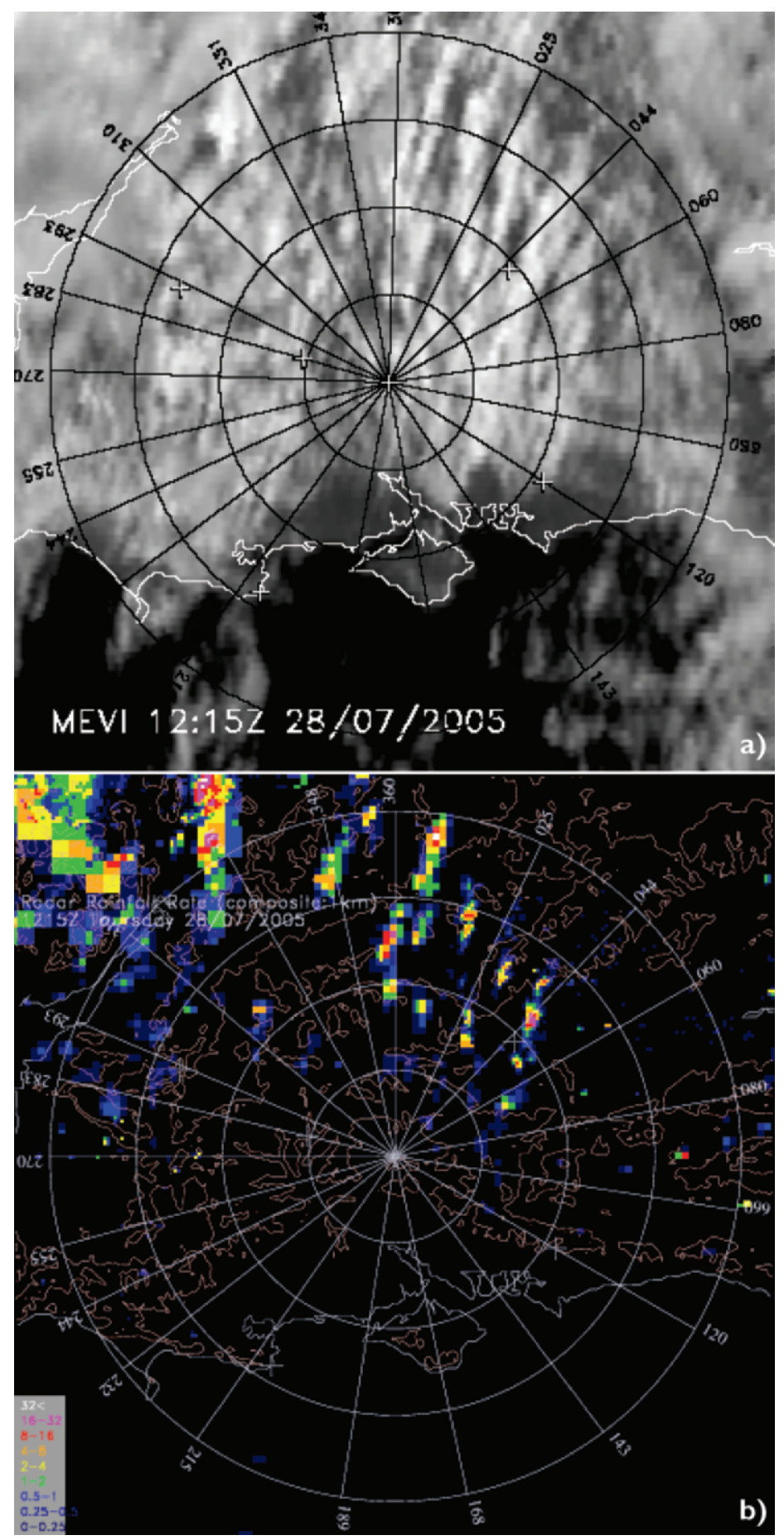

FIG. I2. (a) High-resolution visible image from Meteosat-8 (MSG) and (b) rainfall rate from the radar network (key in $\mathrm{mm} \mathrm{h}^{-1}$ ) at I2I5 UTC 28 Jul 2005 (IOP I2), showing convective cloud streets and associated showers and thunderstorms. Range rings are centered on Chilbolton and plotted every $25 \mathrm{~km}$.

2006; Marsham and Parker 2006) indicated that while the first of these was triggered by the cold-pool outflow from an earlier storm that formed upwind of the CSIP area, the other two were triggered by gravity waves ema- 


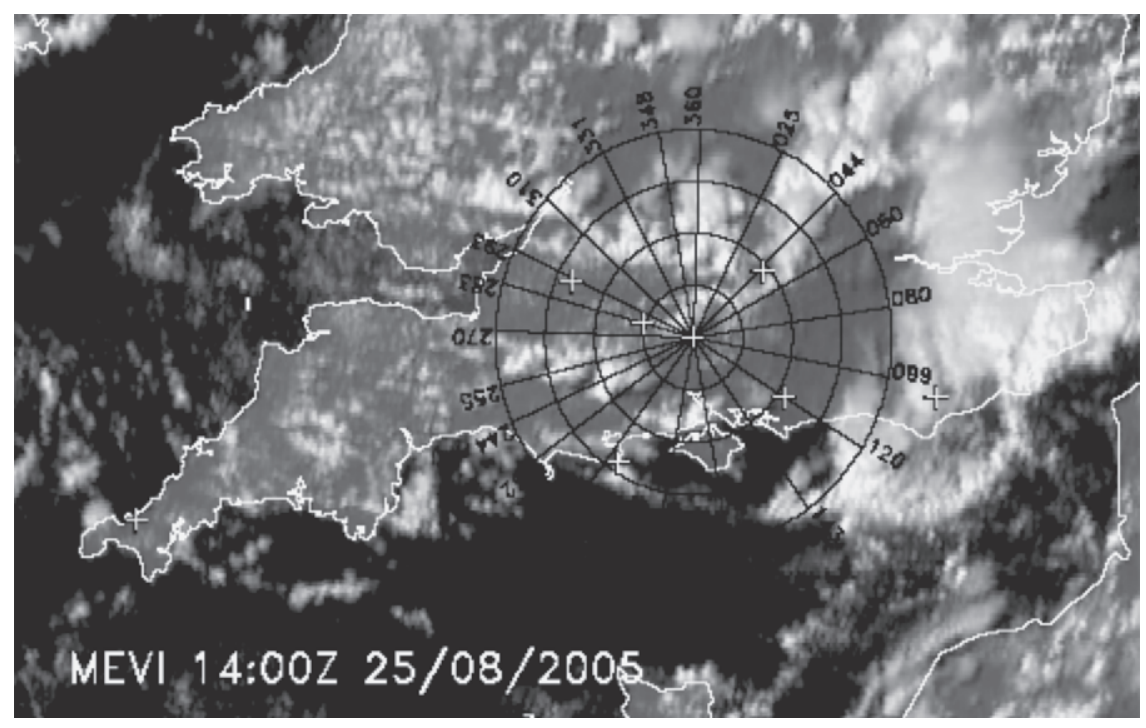

FIG. 13. Same as in Fig. 10, but for 1400 UTC 25 Aug 2005 (IOP I8), showing an arc of convective cloud along a gust front to the southeast of Chilbolton over the English Channel.

nating from the same storm. Radar scans showing the top of the boundary layer were made with the $1275-\mathrm{MHz}$ Chilbolton radar at a number of azimuths before and during the development of these storms. These scans were analyzed so as to map the depth of the boundary layer out to a radius of about $30 \mathrm{~km}$ from Chilbolton
(Fig. 17). A time series of plots like Fig. 17 indicated that the top of the boundary layer was modulated by a traveling gravity wave with a wavelength of $40-50 \mathrm{~km}$ and amplitude of the vertical air parcel displacement of $\pm 150 \mathrm{~m}$. The vertical sounding for this occasion was shown earlier in Fig. 2a, and the accompanying Fig. $2 b$ showed that a gravity wave capable of lifting the lid capping the boundary layer by a mere $150 \mathrm{~m}$ would indeed have been sufficient to enable convection to break through.

Examples of forcing from upper levels.The passage of uppertropospheric PV maxima is the principal forcing mechanism from upper levels. A study by Roberts (2000) has shown that mesoscale PV maxima are abundant and are associated with a large proportion of the thunderstorms encountered in the northeast Atlantic area and in the more maritime parts of northwest Europe. The PV maxima are a)

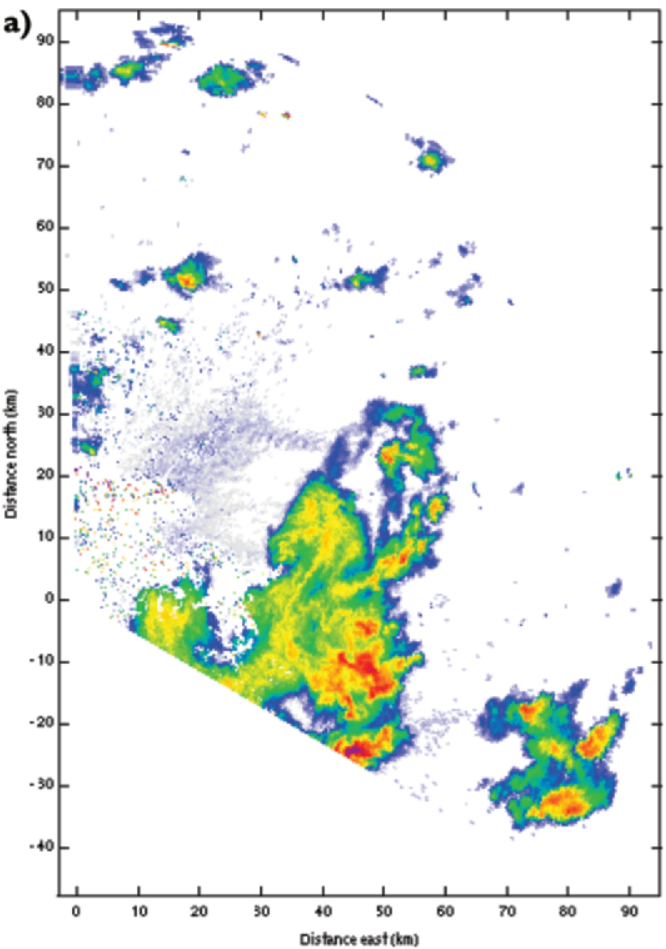

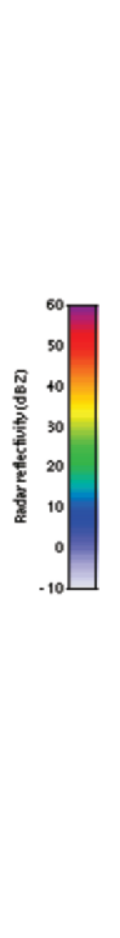

b)

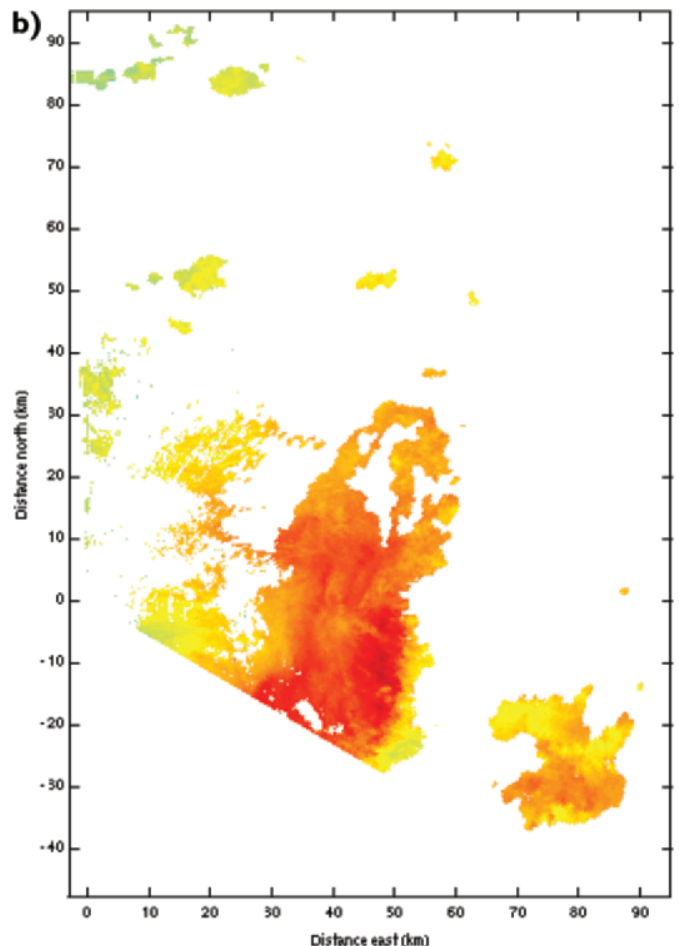

Fig. 14. Example of a cold-pool-outflow convergence line: PPIs at $0.5^{\circ}$ of (a) reflectivity (dBZ) and (b) unfolded Doppler velocity (key in $\mathrm{m} \mathrm{s}^{-1}$ away from radar) at II 57 UTC 25 Aug 2005 (IOP 18), showing the relation between convergence features and the precipitation field. 

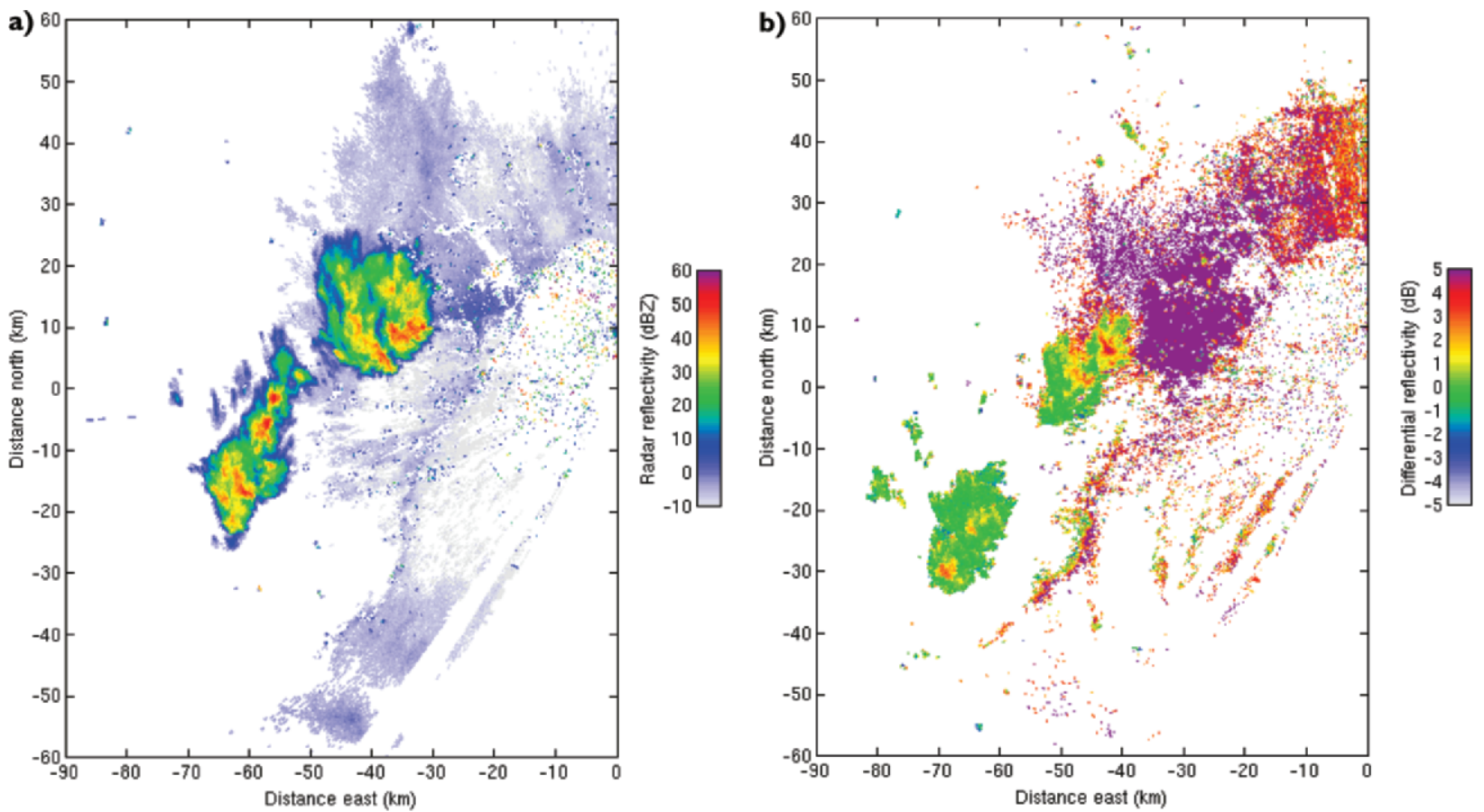

FIG. I5. PPIs at $0.5^{\circ}$ of (a) reflectivity (dBZ) at I70I UTC and (b) differential reflectivity (dB) at I622 UTC 18 Aug 2005 (IOPI6), showing a radar fine line associated with a gust front.

important for convection because of the associated patterns of advection and vertical motion. Advection of cold air into the upper and middle troposphere increases the CAPE and the ascent weakens the lid, that is, reduces CIN. Because the cold air is also very dry, it is often easily detected in satellite water vapor (WV) imagery and gives rise to the familiar WV dark zone (Browning 1997). The analysis of WV imagery formed the basis of Roberts' analysis. An example from CSIP is given in Fig. 18, which shows a WV dark zone centered over central England. In the middle of the dark zone (due north of the Isle of Wight and east of south Wales) is a very small gray dot that corresponds to an isolated thunderstorm. This storm occurred on the occasion depicted in Figs. 10 and 11. Detailed analysis shows it to have been due to the combined effects of the upper-level PV maximum and the coastally induced low-level convergence line discussed earlier, which on its own produced only shallow convective showers.

The final example of an upper-level influence on convection initiation is shown in Fig. 19. Figure 19a shows a Eumetsat cloud-height product diagnosed from MSG satellite infrared channels. Figure 19b shows the corresponding visible image and Fig. 19c shows the radar network display for the same time. Orphaned anvils from decayed thunderstorms that had traveled northward from France are shown orange in Fig. 19a; they appear as fuzzy light gray veils in Fig. 19b. The shadowing from these anvils is thought to have slowed down the diurnal heating of the boundary layer very slightly, but just enough to account for the first deep convective cells being initiated outside or on the boundaries of the

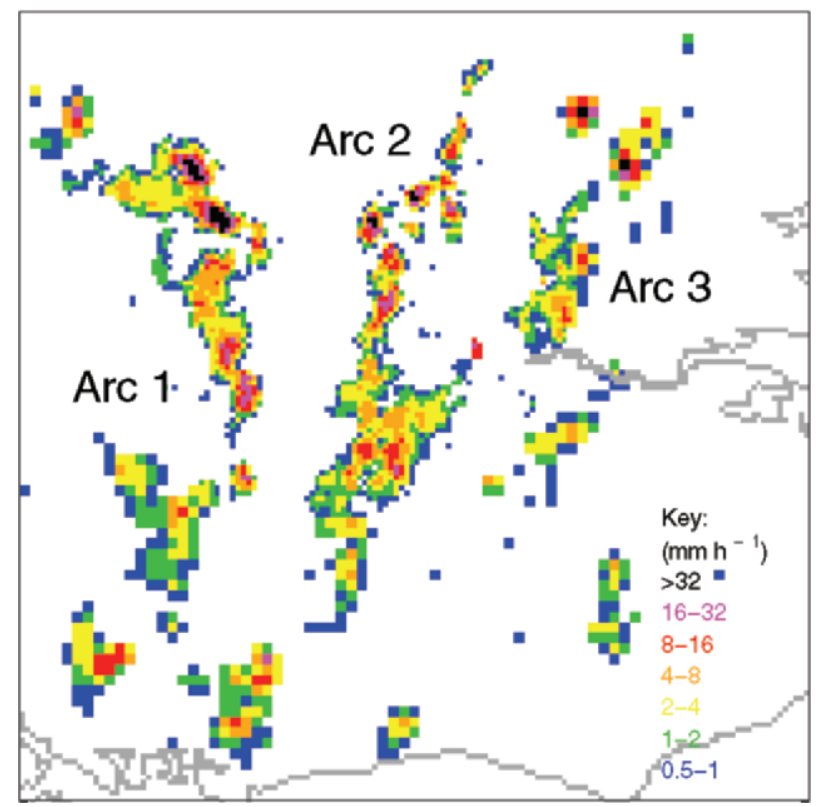

FIG. 16. Rainfall rate $\left(\mathrm{mm} \mathrm{h}^{-1}\right)$ over a $150 \mathrm{~km} \times 150 \mathrm{~km}$ region of southern England at II30 UTC 10 Jul 2004, showing a series of bands of convective precipitation that had been triggered by a gravity wave generated by an earlier storm. (From Morcrette et al. 2006.) 


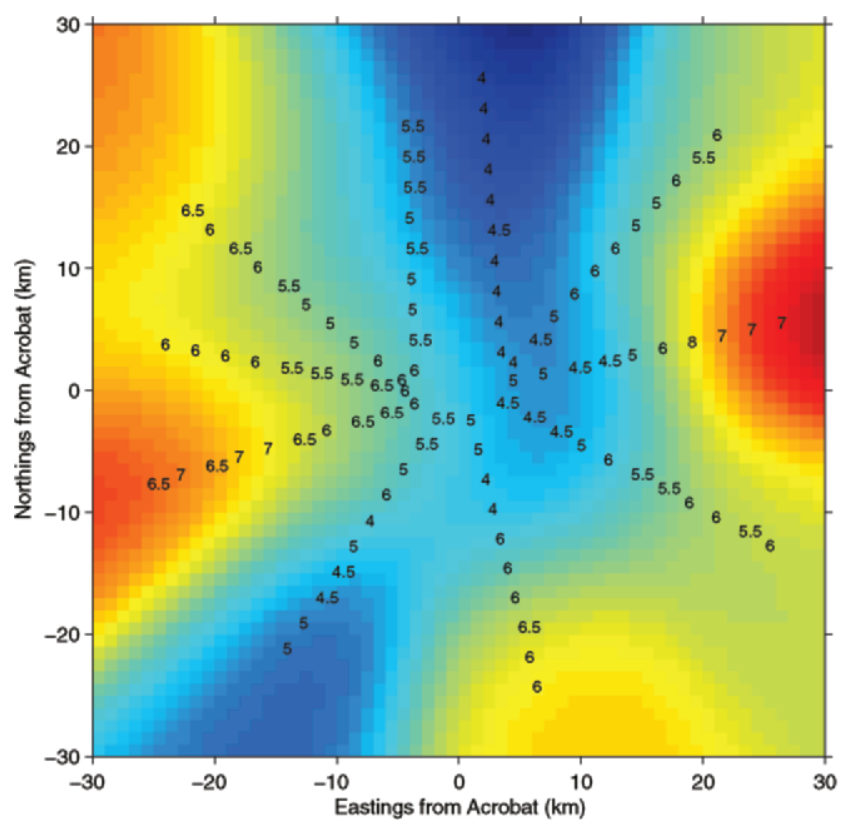

shadowed areas. The deep convection cells show up as bright clouds on the visible image (Fig. 19b). A few of these clouds were already developing into showers at this time (Fig. 19c) and some of them developed into thunderstorms that produced flash floods.

\section{USING CSIP RESULTS TO DEVELOP A} HIGH-RESOLUTION NWP MODEL. The

4-km model discussed above is an intermediate step toward a nowcasting NWP system under develop-

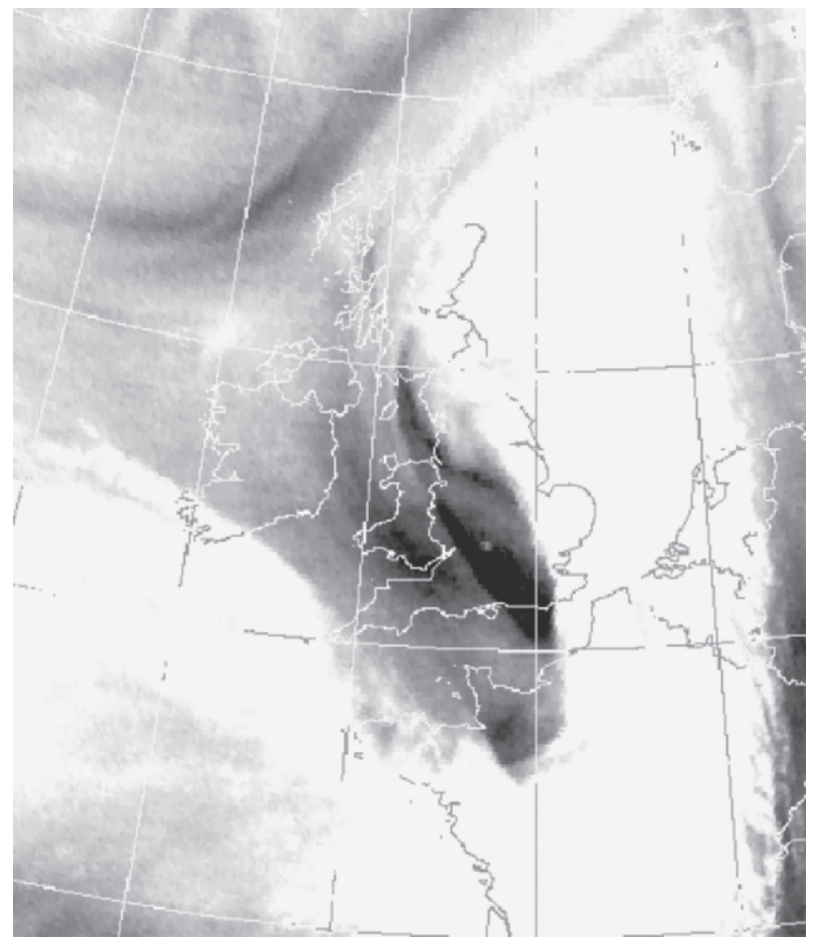

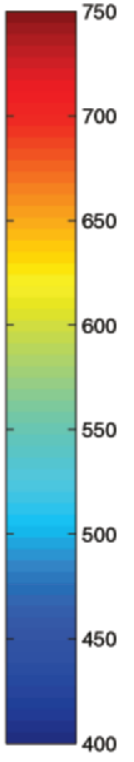

Fig. 17. Height of boundary layer top (hundreds of meters), with interpolated heights shown in color (according to the key, in meters) as derived from $10 \mathrm{RHI}$ scans with the I275-MHz Chilbolton radar. The variation in height is believed to be due to the gravity wave that triggered the precipitation bands in Fig. 16. The scans were obtained from 075 I to 0807 UTC, and their positions have been displaced to correspond to 0758 UTC assuming a system velocity of $8 \mathrm{~m} \mathrm{~s}^{-1}$ from the west. (From Morcrette et al. 2006.)

ment within JCMM that aims to produce very short range forecasts (0-6h) using an NWP system based on a version of the Unified Model with horizontal resolution around $1 \mathrm{~km}$. The performance of such a system can loosely be considered to depend on performance at three separate scales.

At the coarsest scale, the synoptic and mesoscale events determine the overall region where convection may occur. In practice, such regions are represented well by the current generation of operational NWP systems. However, analysis errors are still present for important features such as small $(\sim 50 \mathrm{~km})$ upper-level PV anomalies or low-level areas of enhanced moisture due to inadequacy of observations or the methods used to assimilate them.

Within this general region, there may be areas where instability triggers preferentially. As discussed above, these areas may be convergence lines due to surface forcing (e.g., sea breezes) or due to previous storm outflows, or more two-dimensional regions due to other mechanisms. It is important to understand the mechanisms responsible for these areas so that the NWP model system can be designed to represent them accurately. For example, the representation of stable "lids" is likely to depend on vertical resolution, while the representation of surface-forced convergence lines may depend

FIG. 18. Rapid-scan Meteosat WV image at I200 UTC 15 Jun 2005 (IOP I), showing a thunderstorm (very small gray dot) within a WV dark zone. The image is enhanced to clarify the position of this thunderstorm with respect to the dark zone; although the surrounding white areas are saturated, there is no information in these areas relevant to the discussion. Because the thunderstorm was shallow, it does not show up as a major feature in the WV imagery, which is sensitive mainly to features in the upper troposphere. 

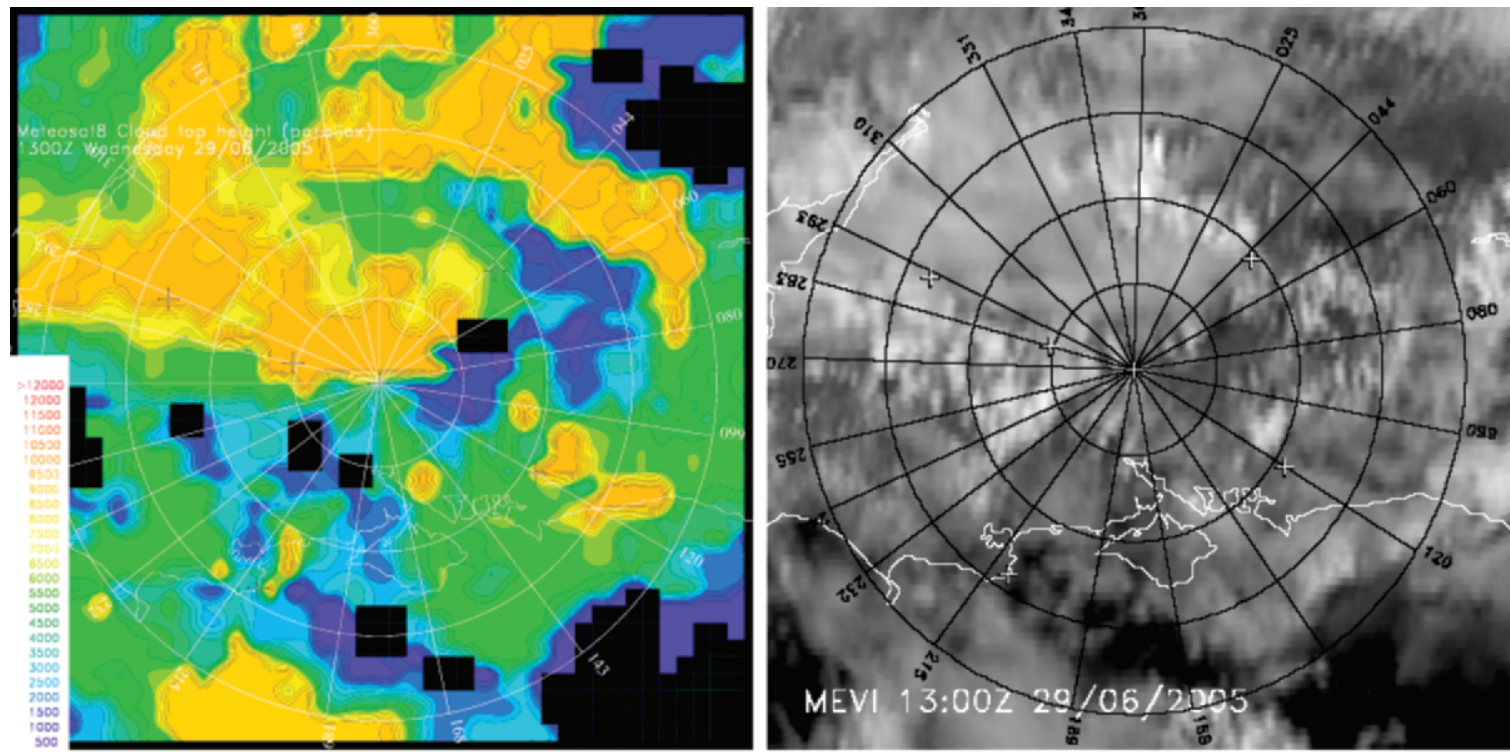

a)

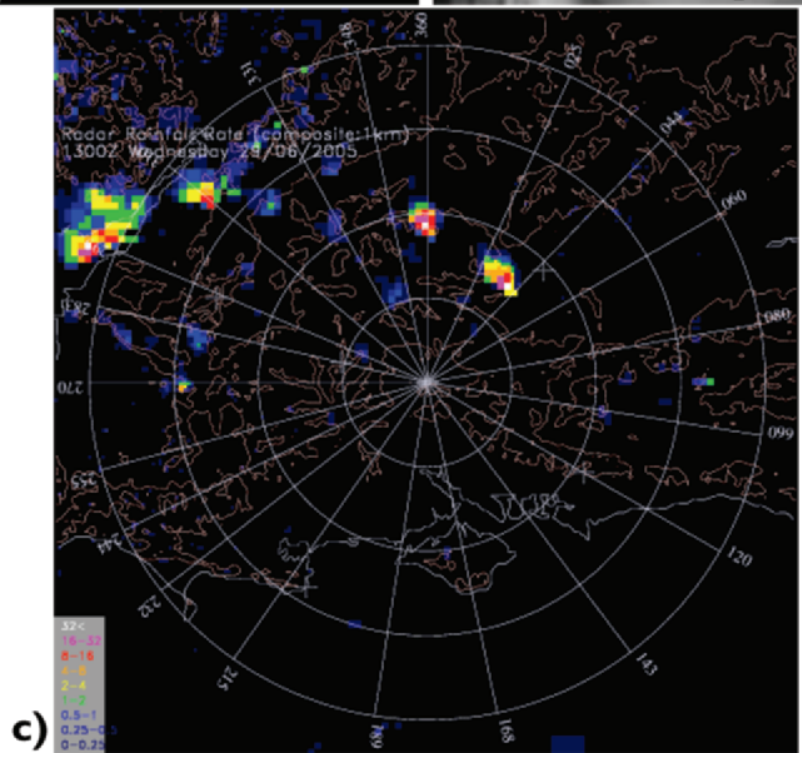

b)

FIG. 19. (a) Cloud-top height (m) derived from MSG infrared data, (b) MSG high-resolution visible image, and (c) radar network rainfall rate, at 1300 UTC 29 Jun 2005 (IOP 5), showing the possible effect of shadowing by cirrus anvils on the formation of new convective clouds. Range rings are centered on Chilbolton and plotted every $25 \mathrm{~km}$.

on surface orography and sea and land surface temperatures, and hence surface exchange processes. On the other hand, the development of convergence lines from storm downdrafts depends on the treatment of cloud dynamics and microphysics, as well as boundary layer processes. The CSIP data are being used to validate and optimize the model formulation as well as to investigate the predictability of storms in the presence of different initiation mechanisms. Distinguishing between these mechanisms is important because many of them operate before significant precipitation is observed by operational radar systems, and understanding them can help in the design of observing and assimilation systems.
On the smallest scale-within, for example, mesoscale convergence lines-individual storm cells develop. It is extremely unlikely that the location of such cells is generally predictable even within a very high resolution model. In a model with $\sim 1-\mathrm{km}$ resolution, cells develop from features (such as small cumulus clouds) that are not explicitly resolved in the model. In practice, we find that the model behavior in generating individual cells depends critically on the representation of turbulence and its interaction with model dynamics, and that existing techniques require improvement. Two (related) approaches are conceivable. First, the transition from unresolved 

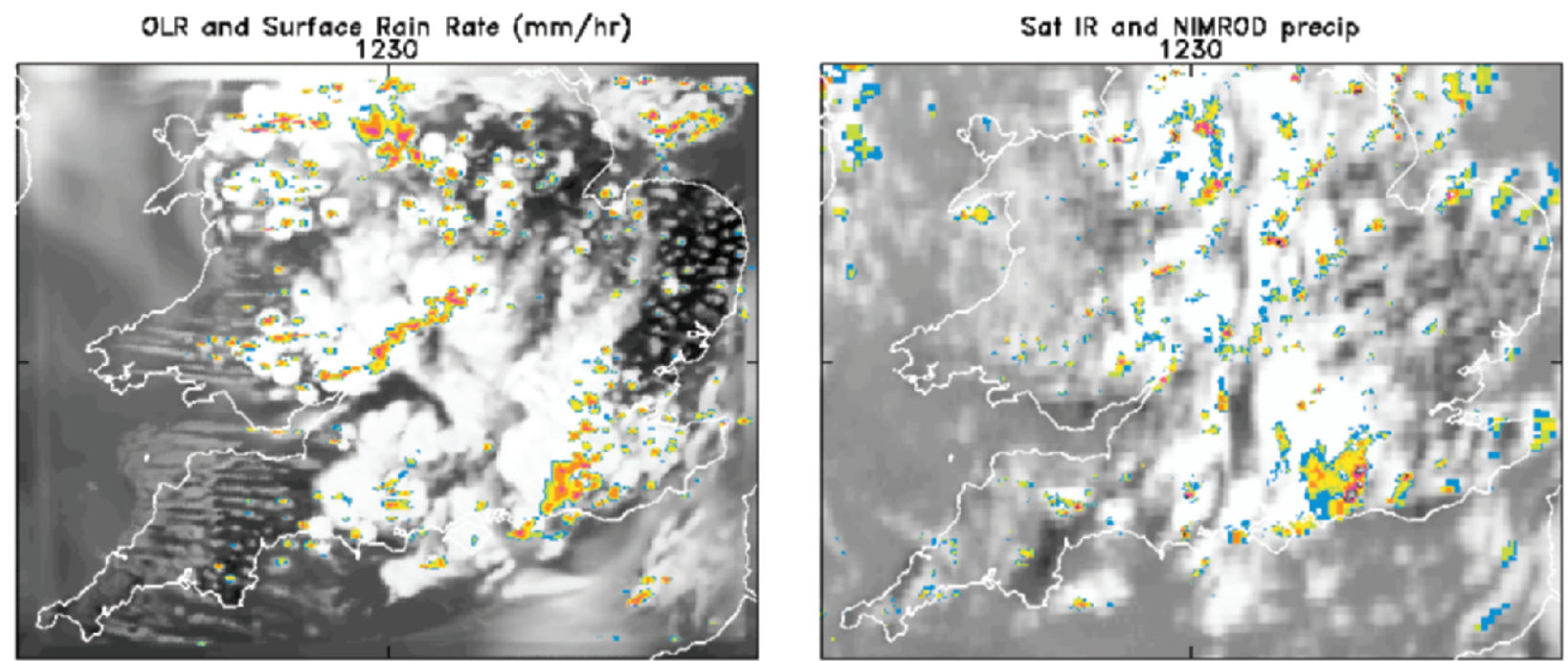

FIG. 20 (a) Unified Model 6.5-h forecast of broadband IR radiance temperature and surface rainfall rate compared with (b) observational analysis showing NIMROD-derived rainfall rate (colors) superimposed on IR satellitederived cloud (white), at I230 UTC 25 Aug 2005 (IOP I8).

turbulence to explicit cells may be treated via "stochastic backscatter," that is, adding a well-defined random component to physical parameterizations in the model. Second, understanding of these upscale transport mechanisms may enable new observing techniques (such as clear-air radar) to be used to detect regions that may develop into cells and thus modify the model state with sufficient lead time to produce useful forecasts of subsequent precipitation. The CSIP data are providing a valuable source of validation data to improve our representation of these parameterization and assimilation issues.

Figure 20 shows an example of modeling progress so far for one of the cases discussed above (see Figs. 13 and 14). The figure shows a representation of broadband IR radiance temperature and surface rainfall rate from a 1.5-km, 76-level model compared with observed MSG satellite IR radiance temperature and analyzed radar rainfall using the NIMROD system. Figure 20a is $\mathrm{a} \mathrm{T}+6.5-\mathrm{h}$ forecast, and it is notable that the organized area of showers over southern England is quite well forecast, if a little too far to the east. The role of the west coast is also clear in the forecast from the cloud streets that originate at or near the coast. Although their presence in observations is not obvious from the IR image in Fig. 20b, which struggles to resolve them, the visible MSG image in Fig. 13 hints at them and an even higher resolution visible Moderate Resolution Imaging Spectroradiometer (MODIS) image (not shown) depicts them very clearly.

In summary, the Convective Storm Initiation Project (CSIP) was an international field campaign designed to observe the process responsible for the initiation of convection in the United Kingdom. It was highly successful and provided unparalleled observations with which to understand and quantify these processes. Real progress is being and will continue to be made on improving forecasts of convective storms as a result of CSIP.

ACKNOWLEDGMENTS. We are grateful to Carolyn Cook, Alec Bennett, Nicky Chalmers, Helen Dacre, Laura Davies, Anna Fitch, Sarah Keeley, and Alexander Richardson from the University of Reading; Markus Engelhardt, Roger Huckle, and Katrin Zink from Universität Karlsruhe; and Duncan Hodges and Mark Vowles from the University of Bath for launching so many radiosondes. Olaf Stiller, of JCMM, helped in the forecast center at the University of Reading. Charles Kilburn and Ag Stephens of BADC, provided nearreal-time data products for forecasting and planning, and BADC provided workspaces and archiving of all data.

Martin Hill designed the AWSs; Ralph Burton assisted in building them; James Groves assisted in deploying them; and Matt Hobby and Volker Horlacher assisted with various aspects of the design. Martin Gallagher and Peter Kelly assisted in operating the Cessna aircraft. Charles Wrench helped with critical aspects of organizing the field campaigns and operating the UV Raman lidar. Andrew Barkwith, from the University of Salford, assisted with the Doppler lidar during the field campaigns. John Goddard and the staff at Chilbolton Observatory-Owain Davies, Jan Lass, Eric Threlfall, Dave King, and Mal Clarke-hosted the field campaigns and provided exceptional service.

CSIP exploited new instruments available through the U.K. Universities' Facility for Atmospheric Measurement (UFAM), which is funded by the National Environment 
Research Council following an initial award from the HEFCE Joint Infrastructure Fund. Operational observational and forecast data were provided by the Met Office. Satellite images are from Eumetsat. The Chilbolton Observatory, around which the project was based, is owned by the Science and Technology Facilities Council.

\section{REFERENCES}

Barthlott, Ch., U. Corsmeier, C. Meißner, F. Braun, and Ch. Kottmeier, 2006: The influence of mesoscale circulation systems on triggering convective cells over complex terrain. Atmos. Res., 81, 150-175.

Bennett, L. J., K. A. Browning, A. M. Blyth, D. J. Parker, and P. A. Clark, 2006: A review of the initiation of precipitating convection in the United Kingdom. Quart. J. Roy. Meteor. Soc., 132, 1001-1020.

Bougeault, P., and Coauthors, 2001: The MAP special observation period. Bull. Amer. Meteor. Soc., 82, 433-462.

Browning, K. A., 1997: The dry intrusion perspective of extra-tropical cyclone development. Meteor. Appl., 4, 317-324.

— , and Coauthors, 2006: A summary of the Convective Storm Initiation Project intensive observation periods. Forecasting Research Tech. Rep. 474, 137 pp. [Available online at www.metoffice.gov.uk/research/ nwp/publications/papers.]

Cullen, M. J. P., 1993: The unified forecast/climate model. Meteor. Mag., 122, 81-94.

Davies, T., M. J. P. Cullen, A. J. Malcolm, M. H. Mawson, A. Staniforth, A. A. White, and N. Wood, 2005: A new dynamical core for the Met Office's global and regional modelling of the atmosphere. Quart. J. Roy. Meteor. Soc., 131, 1759-1782.

Doviak, R. J., and D. S. Zrnic, 1993: Doppler Radar and Weather Observations. 2d ed. Academic Press, 562 pp.

Fabry, F., 2006: The spatial variability of moisture in the boundary layer and its effect on convection initiation: Project-long characterization. Mon. Wea. Rev., 134, 79-91.

—, C. Frush, I. Zawadzki, A. and Kilambi, 1997: Extracting near-surface index of refraction using radar phase measurements from ground targets. J. Atmos. Oceanic Technol., 14, 978-987.

Goddard, J. F. W., J. D. Eastment, and M. Thurai, 1994: The Chilbolton Advanced Meteorological Radar: A tool for multidisciplinary atmospheric research. Electron. Comm. Eng. J., 6, 77-86.

Golding, B. W., 1998: Nimrod: A system for generating automated very short range forecasts. Meteor. Appl., $5,1-16$.

Gregory, D., and P. R. Rowntree, 1990: A mass flux convection scheme with representation of cloud ensemble characteristics and stability-dependent closure. Mon. Wea. Rev., 118, 1483-1506.

Hoskins, B. J., M. E. McIntyre, and A. W. Robertson, 1985: On the use and significance of isentropic potential vorticity maps. Quart. J. Roy. Meteor., 111, 877-946.

Jones, C. D., and B. Macpherson, 1997: A latent heat nudging scheme for the assimilation of precipitation data into an operational mesoscale model. Meteor. Appl., 4, 269-277.

Lorenc, A. C., and Coauthors, 2000: The Met. Office Global 3-Dimensional Variational Data Assimilation Scheme. Quart. J. Roy. Meteor. Soc., 126, 2991-3012.

Marsham, J. H., and D. J. Parker, 2006: Secondary initiation of multiple bands of cumulonimbus over southern Britain. Part II: Dynamics of secondary initiation. Quart. J. Roy. Meteor., 132, 1053-1072.

Morcrette, C. J., K. A. Browning, A. M. Blyth, K. E. Bozier, P. A. Clark, D. Ladd, E. G. Norton, and E. Pavelin, 2006: Secondary initiation of multiple bands of cumulonimbus over southern Britain. Part I: An observational case study. Quart. J. Roy. Meteor. Soc., 132, 1021-1051.

Purdom, F. J. W., 1982: Subjective interpretation of geostationary satellite data for nowcasting. Nowcasting, K. A. Browning, Ed., Academic Press, 149-166.

Roberts, N. M., 2000: The relationships between water vapour imagery and thunderstorms. JCMM Internal Rep. 110, 40 pp. [Available from Joint Centre for Mesoscale Meteorology, Dept. of Meteorology, University of Reading, P.O. Box 243, Reading RG6 6BB, United Kingdom.]

Schmetz, J., P. Pili, S. Tjemkes, D. Just, J. Kerkmann, S. Rota, and A. Ratier, 2002: An introduction of Meteosat Second Generation (MSG). Bull. Amer. Meteor. Soc., 83, 977-992.

Weckwerth, T. M., 2000: The effect of small-scale moisture variability on thunderstorm initiation. Mon. Wea. Rev., 128, 4017-4030.

— initiation and motivation for IHOP_2002.Mon. Wea. Rev., 134, 5-22.

- , and Coauthors, 2004: An overview of the International $\mathrm{H}_{2} \mathrm{O}$ Project (IHOP_2002) and some preliminary highlights. Bull. Amer. Meteor. Soc., 85, 253-277.

Wilson, J. W., and W. E. Schreiber, 1986: Initiation of convective storms at radar-observed boundary-layer convergence lines. Mon. Wea. Rev., 114, 2516-2536.

— , and R. D. Roberts, 2006: Summary of convective storm initiation and evolution during IHOP: Observational and modeling perspective. Mon. Wea. Rev., 134, 23-47. 